
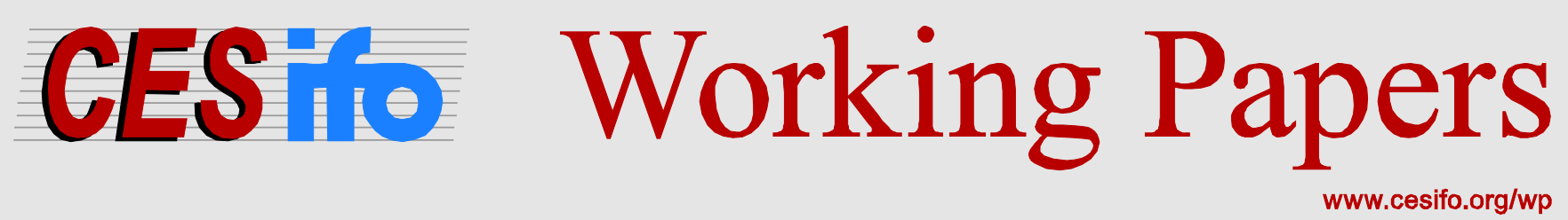

\title{
Wages, Human Capital, and Structural Transformation
}

\author{
Berthold Herrendorf \\ Todd Schoellman
}

\author{
CESIFO WORKING PAPER NO. 6426 \\ CATEgORY 6: Fiscal POLICY, MACROECONOMICS AND GROWTH \\ MARCH 2017
}

An electronic version of the paper may be downloaded

- from the SSRN website:

- from the RePEc website:

- from the CESifo website:

www.SSRN.com

www.RePEc.org

www.CESifo-group.org/wp 


\title{
Wages, Human Capital, and Structural Transformation
}

\begin{abstract}
Average wages are considerably lower in agriculture than in the other sectors. We document this fact for thirteen countries ranging from rich (Canada, U.S.) to poor (India, Indonesia). We develop a measure of human capital that accounts for the selection of workers with different unobserved skills into sectors. We find that differences in human capital account for most of the wage gaps. We develop a model that rationalizes this finding and that allows us to quantify the distortions to the allocation of labor. We find that they are considerably smaller than typically claimed in the literature.
\end{abstract}

JEL-Codes: O100.

Keywords: human capital gaps, misallocation of labor, wage gaps.

\author{
Berthold Herrendorf \\ Department of Economics \\ W.P. Carey School of Business \\ Arizona State University \\ USA - Tempe, AZ 85287-9801 \\ berthold.herrendorf@asu.edu
}

\author{
Todd Schoellman \\ Department of Economics \\ W.P. Carey School of Business \\ Arizona State University \\ USA - Tempe, AZ 85287-9801 \\ todd.schoellman@gmail.com
}

\section{March 24, 2017}

For helping us with the data, we would like to thank Adam Blandin. For helpful discussions and suggestions, we would like to thank Douglas Gollin, Alessio Moro, Ákos Valentinyi, Gustavo Ventura, Roberto Samaniego, Michael Waugh, and the audience of presentations at ASU, Católica de Chile, Indiana, Mannheim, Notre Dame, UCSD, the Christmas Meetings of the German Expat Economists in Kiel, the Conference on "Structural Change and Macroeconomic Dynamics" in Paris, the Conference on "Urbanization, Structural Change, and Employment" at HKUST, the NBER Summer Institute (Growth Meeting), the RIDGE Workshop on "Productivity Growth, Resource Misallocation and Development", and the SED Meetings in Toronto. We thank the National Statistical Offices of the respective countries for making their data available through IPUMS - International. Herrendorf thanks the Spanish Ministry of Education for research support (Grant ECO2012 \{31358). The usual disclaimer applies. 


\section{Introduction}

In his Nobel prize lecture, Kuznets (1973) named the process of structural transformation as one of the six main features of modern economic growth. In this paper, we focus on a particular aspect of structural transformation, namely the reallocation of labor from agriculture to the other sectors of the economy ("non-agriculture"). Perhaps surprisingly there are two rather different views within the macro-development literature of this aspect of structural transformation. One strand of the literature assumes that labor is allocated efficiently between sectors and then characterizes the properties of preferences and technological progress that generate the reallocation of labor from agriculture to non-agriculture as a consequence of growth. Herrendorf et al. (2014) provide a review of that strand of the literature. ${ }^{1}$ In contrast, a second strand of the literature measures large gaps in labor productivity between non-agriculture and agriculture and, since it is difficult to account for these gaps, concludes that labor must be allocated inefficiently between sectors, with the reallocation of labor from agriculture to non-agriculture in poor countries hindered by some sort of barriers to movement of people; see e.g. Caselli and Coleman (2001), Caselli (2005), Restuccia et al. (2008), Vollrath (2009), and McMillan and Rodrik (2011). According to this logic, the removal of barriers would allow labor to move out of agriculture, which would generate growth. This is precisely the opposite direction of causality from that in the first strand of the literature. It follows that given the same stylized fact these two strands of the macro-development literature will make completely different policy prescriptions.

These two different views coexist in the literature because there is little hard evidence on whether or not the allocation of labor between agriculture and the other sectors is efficient. The contribution of this paper is to provide such evidence for multiple years and thirteen countries ranging from rich (Canada, U.S.) over middle income (Brazil, Mexico) to poor (India, Indonesia). Our sample of countries covers $30 \%$ of the world population and includes four of the five most populous countries (namely, India, the U.S., Indonesia, Brazil). The selection criteria for being included in the sample is that we have sufficiently detailed data to be able to calculate wages and construct human capital at the sectoral level. ${ }^{2}$ For the U.S. the data are from the CPS, the Census, and the American Community Survey (ACS) and they cover the period 1960-2015. For the other twelve countries, the data are

\footnotetext{
${ }^{1}$ Key contributions to it include Key contributions to it include Echevarria (1997), Kongsamut et al. (2001), Ngai and Pissarides (2007), Rogerson (2008), Buera and Kaboski (2012), Herrendorf et al. (2013), Boppart (2014), and Herrendorf et al. (2015).

${ }^{2}$ Barro and Lee (2010), which is the standard data source for quality-adjusted human capital stocks around the world, does not contain the schooling and wage information at the sector level that we require for our analysis.
} 
from 32 population censuses that are harmonized by the Integrated Public Use Microdata Series (IPUMS) International, Minnesota Population Center (2015), and range from 1970 to 2010. We document that in all countries there are large gaps between the average wages per hour in non-agriculture and agriculture. We decompose the wage gaps into differences in the average sectoral human capital of workers (appropriately constructed) and residual wage gaps. We view the result of this decomposition through the lens of a sorting model and derive bounds on the distortions to the allocation of labor between agriculture and non-agriculture.

We start by analyzing the period 1980-2015 for the U.S. for which we have the most detailed data. Since non-agriculture is a rather large and heterogenous sector, we disaggregate it into industry, unskilled services, and skilled services. ${ }^{3}$ We document that even in the U.S. there are large gaps in average hourly wages: average workers in industry, unskilled services, and skilled services take home $67 \%, 32 \%$, and $80 \%$ more per hour than an average worker in agriculture. A natural explanation for these wage gaps is that average human capital is higher in non-agriculture than in agriculture. We document that indeed an average worker in non-agriculture went to school for two-and-a-half more years than an average worker in agriculture, and between skilled services and agriculture the difference is as large as three-and-a-half years. It is not immediately obvious, however, how to translate gaps in years of schooling into gaps in human capital. A useful first step is to use the off-the-shelf Mincer returns that have been estimated for the aggregate economy and that are widely used in the development literature. Employing the numbers from Banerjee and Duflo (2005), we find that this all but closes the wage gaps between unskilled services and agriculture, but leaves sizable residual wage gaps between the other two non-agricultural sectors and agriculture. For example, per unit of human capital ("efficiency unit") the wage of an average worker in skilled services still is $40 \%$ higher than that of an average worker in agriculture.

One might be tempted conclude from this finding that even in the U.S. there are large barriers that distort the efficient allocation of labor between agriculture and the service sectors. Since that conclusion seems rather implausible, a more likely explanation is that aggregate Mincer returns capture only part of sectoral human capital. Indeed, estimating Mincer returns to schooling by sector, we find that they are larger in services than in agriculture. Moreover, using sectoral Mincer returns to construct human capital, it turns out that the resulting human capital gap between services and agriculture accounts for

\footnotetext{
${ }^{3}$ For completeness, Online Appendix B.2 also provides results for the finer fifteen-sector split that IPUMS uses.
} 
almost the entire wage gap. This leaves the wage gaps between industry and agriculture to explain. We find that Mincer returns in industry are actually similar to those in agriculture, implying that a residual average wage premium of around twenty percent over agriculture remains no matter how we construct human capital. This wage premium is mostly due to large wage premia in construction and especially mining, which we conjecture compensate workers for the working conditions there.

Our results raise the question why workers in services experience higher Mincer returns to schooling than workers in the other sectors. We consider two possible answers. The "sectoral hypothesis" attributes the differences in Mincer returns to differences in sectoral technologies: schooling generates more human capital for a worker with the same characteristics in services than in the other sectors. In contrast, the "selection hypothesis" attributes the differences to differences in workers' characteristics: schooling generates the same human capital in each sector, but workers sort so that those who have higher innate ability and therefore learned more per year of schooling work in services. This type of sorting leads to higher observed Mincer returns to schooling in services. Both views have the potential to explain why services have higher Mincer returns than the other sectors. To help us distinguish between them, we study the qualitative implications in a simple multi-sector model in which workers are endowed with years of schooling and innate ability and choose in which sector they work. To be able to speak to the sectoral hypothesis, we allow for the possibility that sector technologies differ in the returns to human capital.

We show the following results. If the returns to human capital are larger in the service sectors than in agriculture, then workers in agriculture must be compensated by a wage payment that is independent of years of schooling. In terms of the Mincer regression of log wages in years of schooling, a larger wage payment that is independent of years of schooling implies a larger intercept in agriculture than in the service sectors. Moreover, absent any barriers for moving to the service sectors, the differences in the intercepts are indicative of how important the sectoral hypothesis is compared to the selection hypothesis. Given that the differences in the intercepts are fairly small in the data compared to the overall wage gaps, our theory suggests that selection hypothesis is more important for explaining our findings than the sectoral hypothesis, that is, most of the observed differences in Mincer returns between the service sectors and agriculture are due to differences in the unobserved characteristics of workers across sectors.

The CPS has a panel dimension that allows us to provide direct evidence in favor of this prediction of our model. Specifically, households are in the CPS for four months, then out for eight months before returning for four more months. We can match the fourth month of each 
spell when extra data are collected (the so-called "outgoing-rotation groups"). Studying the average wages of workers who switch sector during the twelve months between two outgoing-rotation-group observations, we find that on average switching from one sector to another closes at most one quarter of the initial average wage gap between the sectors. This means that the selection account accounts at least for three quarters of the initial average wage gap between the sectors.

The qualitative features of our findings generalize to our sample of thirteen countries. In particular, we again find that there are sizable wage gaps between the non-agricultural sectors and agriculture, with the largest gaps between skilled services and agriculture. ${ }^{4}$ Most of the wage gaps are accounted for by differences in human capital: non-agricultural workers, in particular in skilled services, again have more years of schooling and earn higher Mincer returns on schooling. Using sectoral human capital constructed with sector-specific Mincer returns, we again close most of the wage gaps between the service sectors and agriculture whereas a sizable wage gap remains between industry and agriculture. Since now it is plausible to allow for barriers of moving between sectors, we also study how potentially important barriers are for explaining the residual wage gaps. Assuming that the entire residual wage gaps are due to barriers provides an upper bound for their importance. Doing this, we find that the potential role for barriers is much smaller than in studies like Restuccia et al. (2008), who worked off indirect evidence from labor productivity gaps instead of direct evidence from wage gaps.

Our work has several important implications. To begin with, our finding that even in poor countries like India and Indonesia the potential role for barriers is limited suggests that reality is closer to the first than the second view of structural transformation outlined above, and that the scope for policy reforms that aim to generate growth by removing barriers to the allocation of labor is limited. It is important to keep in mind that this statement is purely about the allocation of wage workers, and so has nothing to say about the importance of barriers to the allocation of capital, proprietors, land, or intermediate goods. Second, our work implies that to construct human capital at the sector level one also has to take into account selection according to unobserved characteristics like innate ability, not only selection according to observed characteristics like years of schooling. Our analysis shows that Mincer returns that are estimated at the sectoral level deliver this, whereas Mincer returns that are estimated at the aggregate level miss the selection according to unobserved characteristics by construction. While we find that this point is quantitatively important for

\footnotetext{
${ }^{4}$ Hnatkovska and Lahiri (2013) argue that urban-rural wage gaps in India have declined in recent years. We remain silent on the behavior of wage gaps over time.
} 
the allocation of labor between the service sectors and agriculture, it is potentially relevant in other contexts as well.

The remainder of the paper is organized as follows. In the next section, we briefly review the most closely related literature. We then present our basic findings for the U.S. Section 4 views the basic findings through the lens of a simple multi-sector model. Section 5 presents evidence for the U.S. from workers who switch sector. Section 6 extends the U.S. analysis to 39 censuses from thirteen countries. Section 7 concludes and provides suggestions for future research.

\section{Related Literature}

Our results are related to those of Gollin et al. (2014), who study misallocation between nonagriculture and agriculture in a large set of poor countries. Since for most of their countries wage data from population censuses is not available, they rely on data from household surveys which contain household characteristics but have no information on wages. They therefore focus on productivity gaps, which are available from NIPA for most countries,

and they use off-the-shelf Mincer returns that are common across countries. Instead we focus on wage gaps and we use Mincer returns that are estimated on country census data. In terms of results, they find that a sizable part of the productivity gaps between nonagriculture and agriculture remains unaccounted for, whereas we find that human capital differences account for most of the wage gaps.

Our results are also related to Lagakos and Waugh (2013) and Young (2014), who develop variants of the Roy model to study the selection of workers according to unobserved characteristics as a potential explanation for the existence and evolution of productivity gaps. Here we focus on the more direct statistic of interest - wages - and show how selection on unobserved characteristics can be measured in a simple way that is disciplined by micro data.

Lastly, our results are related to Young (2013), who develops a location model in which people with better observed and unobserved characteristics sort into urban areas and individuals with worse observed and unobserved characteristics sort into rural areas. Since our concept of human capital includes observed and unobserved characteristics, this prediction of Young is consistent with our finding that most of the wage gaps between the service sectors and agriculture are accounted for by the fact that workers in the service sectors have more human capital. 


\section{Facts About Sectoral Wages and Human Capital in the U.S.}

\subsection{Overview and Basics}

Our goal in this section is to describe the stylized facts about wages by sector. We first study the U.S. separately because it has the richest data of all countries in our sample. In Section 6, we will turn to the international data and show that broadly similar patterns apply there.

There are two data sets for the U.S. that are nationally representative, have information on wages, schooling, age, and so on, and have a sufficient sample size in agriculture to produce useful statistics: the Current Population Survey (CPS) and the Population Census. In the body of the paper, we will report the results for the monthly CPS. ${ }^{5}$ Online Appendix B.1 shows that the results for the Population Census are similar.

We restrict our attention to the period 1980-2015, because prior to 1980 we lack some of the critical data (in particular on switchers). We focus on the subsample of workers that are typically used in wage regressions, that is, individuals who have valid responses to the questions of interest (industry of employment, income, and so on) and who are firmly attached to the labor force, which we define as being 16-70 years old. We use workers who are employed, work for wages, and report positive wage income for the relevant period. While these restrictions are standard, restricting attention to wage workers is stronger in agriculture than usual because roughly half of the agricultural labor force is self-employed proprietors. We do not study them here because their income represents payments to both capital and labor, and it is unclear how to disentangle the fraction of proprietors' income that is wage income. Moreover, there is evidence showing that proprietors underreport their income by a large amount, implying that we do not want to take their stated income too seriously (Herrendorf and Schoellman, 2015). In contrast, the income of wage workers is clearly due to labor and tends to be more precisely reported.

In the body of the paper, we report results for: agriculture and non-agriculture; agriculture, industry, and services; agriculture, industry, unskilled services, and skilled services. The first two of these splits are common in the literature on structural change. The third split is introduced because services is a big and rather heterogenous category, with subcategories that are rather different [Jorgenson and Timmer (2011), Duarte and Restuccia (2014)]. In Online Appendix B.2, we also report the results for the finer fifteen-sector

\footnotetext{
${ }^{5}$ We obtain the data from NBER CPS.
} 
split used by IPUMS from which we will get the data for our international analysis. ${ }^{6}$ The cross-walk between the four and the fifteen-sector split is as follows:

- Agriculture: agriculture, forestry, and fishing.

- Industry: construction; manufacturing; mining.

- Unskilled services: hotels and restaurants; private household services; communication and transportation; wholesale and retail trade.

- Skilled services: education; financial services and insurance; health; public administration; other services; real estate and business services; utilities.

The dividing line between unskilled and skilled services is the average years of schooling: subsectors in unskilled services have at most 13 years of average schooling and subsectors in skilled services have at least 13 years of average schooling. ${ }^{7}$

\subsection{Stylized Fact 1: Large Raw Wage Gaps}

We start by documenting wage gaps which we define as the ratio of the average wages in a non-agricultural sector and in agriculture. We express wages in current dollars. Depending on what is reported in the data, we calculate wages as the reported hourly wage or the reported weekly earnings divided by the reported hours worked in the prior week. A wage gap larger than one indicates that the average wage in the sector is larger than the average wage in agriculture.

To find the wage gaps, we estimate the following log-wage regression: ${ }^{8}$

$$
\log \left(w_{i j t}\right)=\beta_{t} d_{t}+\beta_{j} d_{j}+\beta_{z} Z_{i j t}+\varepsilon_{i j t}
$$

where $w_{i j t}$ is the hourly wage of individual $i$ in sector $j$ during year $t, d_{t}$ are year dummies, $d_{j}$ is a sector dummy, $Z_{i j t}$ are controls for state and gender, $\beta_{t}, \beta_{j}$, and $\beta_{z}$ are the corresponding coefficients, and $\varepsilon_{i j t}$ is an i.i.d. error term with zero mean. This regression controls for average wage growth and inflation by year through the full set of year dummies and then

\footnotetext{
${ }^{6}$ The data are from IPUMS, Minnesota Population Center (2015).

7 "Other services" comprise all services that are not obviously part of any other category. Examples include "Architectural, engineering, and related services", "Employment services", "Other amusement, gambling, and recreation industries", "Beauty salons", and "Religious organizations". Other services are part of skilled services because they happen to have more than thirteen years of schooling on average.

${ }^{8}$ Since our samples are large and we just estimate straightforward sectoral averages, the point estimates of our regression coefficients are statistically significant at least at the $99 \%$ level. We therefore omit reporting standard errors.
} 
estimates the average sectoral wage. Choosing agriculture as the omitted group, $\exp \left(\beta_{j}\right)$ is the wage gap between sector $j$ and agriculture. The column "Raw wages" of Table 1 shows that this wage gap is sizable. The column "Adjusted wages" of Table 1 shows that controlling for geography and gender, if anything, makes the wage gaps larger. ${ }^{9}$

Table 1: Gaps in Wages and Schooling (U.S. 1980-2015)

\begin{tabular}{lccc}
\hline & Raw wages & Adjusted wages & Years of schooling \\
\hline Non-agriculture & 1.51 & 1.61 & 2.54 \\
1. Industry & 1.65 & 1.67 & 1.67 \\
2. Services & 1.47 & 1.58 & 2.81 \\
2.1 Unskilled services & 1.24 & 1.32 & 1.76 \\
2.2 Skilled services & 1.63 & 1.80 & 3.42 \\
\hline
\end{tabular}

${ }^{a}$ A gap is the ratio of the value of a variable relative to its value in agriculture.

In sum, there are large wage gaps between the non-agricultural sectors and agriculture. This is the stylized fact that we want to shed light on in this paper.

\subsection{Stylized Fact 2: Differences in Observed Characteristics}

A natural explanation for wage gaps is sectoral differences in human capital. Indeed, as the column "Years of schooling" of Table 1 shows, the observable characteristics typically associated with human capital differ across sectors: non-agricultural workers have more years of schooling on average than agricultural workers, with the largest difference between skilled services and agriculture. To assess whether schooling gaps can account for wage gaps, we need to translate years of schooling into human capital. A useful first step is to follow the approach pioneered by Bils and Klenow (2000), who show that under some mild assumptions the log-human capital gain from an additional year of schooling is equal to the log-wage gain ("Mincer return"). We apply this idea in two ways: we first assign every year a constant Mincer return of ten percent, consistent with Banerjee and Duflo (2005); we then work with the actual Mincer returns that we estimate from our data. In this estimation, we follow the common approach in the macro-development literature and do not control for experience. We will control for experience later when we estimate Mincer returns by sector.

\footnotetext{
${ }^{9}$ The main reason for this is that agricultural workers are predominantly male and that male workers earn higher wages on average than female workers. So controlling for gender lowers the wage in agriculture relative to non-agriculture.
} 
Table 2: Gaps in Human Capital and Residual Wages with Aggregate Rates of Return (U.S. 1980-2015)

\begin{tabular}{lcccc}
\hline & \multicolumn{2}{c}{ Rate of return of 0.1 } & \multicolumn{2}{c}{ Estimated rates of return } \\
\cline { 2 - 5 } & Hum. cap. & Res. wages & Hum. cap. & Res. wages \\
\hline Non-agriculture & 1.29 & 1.25 & 1.21 & 1.33 \\
1. Industry & 1.18 & 1.41 & 1.13 & 1.47 \\
2. Services & 1.32 & 1.20 & 1.26 & 1.25 \\
2.1 Unskilled services & 1.19 & 1.11 & 1.13 & 1.17 \\
2.2 Skilled services & 1.41 & 1.28 & 1.34 & 1.35 \\
\hline
\end{tabular}

${ }^{a}$ A gap is the ratio of the value relative to its value in agriculture.

Using the estimated returns to schooling from our data is complicated by the fact that the data are not well fit by a linear return to schooling. Instead, it turns out that wages are a convex function of schooling. This is consistent with recent work by Lemieux (2006) and Binelli (2015). To show the relationship in our data, we estimate regressions that are fully flexible in schooling:

$$
\log \left(w_{i j t}\right)=\beta_{t} d_{t}+\beta_{j} d_{j}+\beta_{n} d_{n}+\beta_{z} Z_{i j t}+\varepsilon_{i j t}
$$

where $d_{n}$ is a full set of dummies for years of schooling. The results are plotted in Figure 1. A clear structural break in the slope arises at roughly twelve years of schooling, which we capture by using the following parsimonious regression:

$$
\log \left(w_{i j t}\right)=\beta_{t} d_{t}+\beta_{j} d_{j}+\beta_{z} Z_{i j t}+\beta_{n} n_{i j t}+\beta_{c} c_{i j t}+\varepsilon_{i j t}
$$

where $n$ is total years of schooling (including years of college) and $c$ is years of college (or university), that is, years of schooling past the twelfth year. This functional form allows for a linear return to schooling $\beta_{s}$ in the standard way, but also captures through $\beta_{c}$ that college has a higher return. ${ }^{10}$

Table 2 shows the human capital gaps and the residual wage gaps using the Banerjee and Duflo (2005) rate of return of 0.1 and using our estimated rates of return. Although the figures differ somewhat, both procedures reach a common conclusion: workers in nonagriculture have more human capital than do workers in agriculture, but the gap is not

\footnotetext{
${ }^{10}$ Note that most of the macro-development literature follows Psacharopoulos (1994) and assumes that wages are a concave function of schooling, which turns out to be at odds with both the CPS and microdata from most other countries; see Binelli (2015).
} 
large enough to explain all of the wage gap, leaving a residual wage gap of up to forty percent. $^{11}$

Figure 1: Convexity in the Returns to Schooling

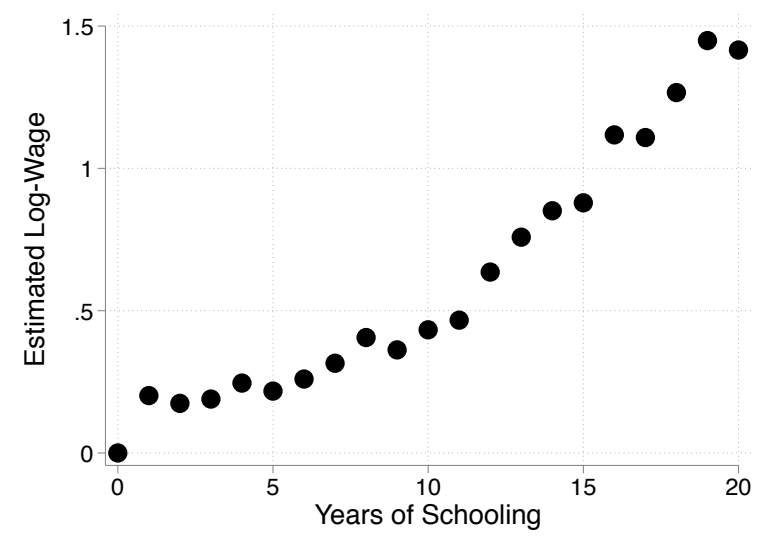

\section{Figure 2: Returns to Schooling Vary by Sector}

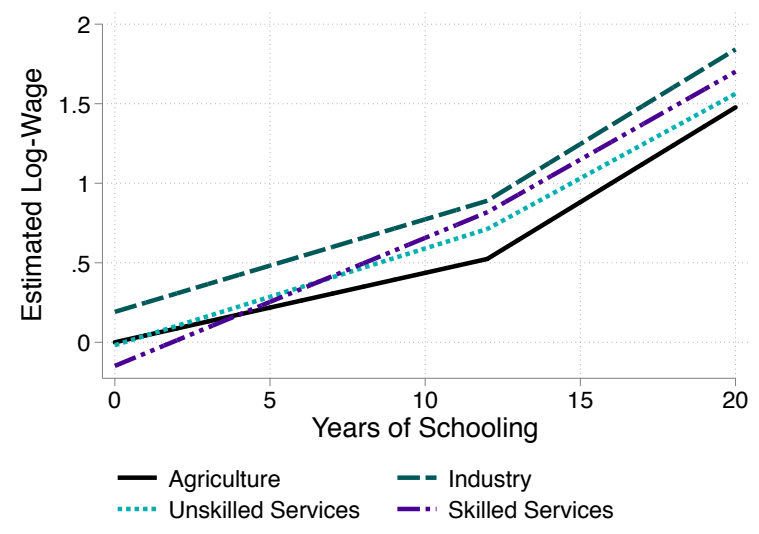

\subsection{Stylized Fact 3: Differences in Sectoral Mincer Returns}

So far, we have constructed human capital under the assumption that the return to a year of schooling is the same in all sectors. Now we relax this assumption and show that the

\footnotetext{
${ }^{11}$ The reason that the figures are larger for the Banerjee and Duflo (2005) returns is that they apply a larger rate of return for the first twelve years of schooling than what we estimate for our data. Since high school last a lot longer than college, this rate of return is the main factor in explaining our results, not the return to years of college.
} 
Mincer returns can differ considerably by sector. To establish this, we run the following regression:

$$
\log \left(w_{i j t}\right)=\beta_{t} d_{t}+\beta_{x} X_{i j t}+\left(\beta_{d j}+\beta_{n j} n_{i j t}+\beta_{c j} c_{i j t}\right) d_{j}+\varepsilon_{i j t}
$$

Since this regression is more in the spirit of what labor people would do, we also include experience as a control where experience is measured as potential experience, that is, age minus years schooling minus six years. We find that $\hat{\beta}_{n j}$ is smallest for agriculture and largest for skilled services and that $\hat{\beta}_{c j}$ are similar for all sectors. A useful way of visualizing this result is by plotting the estimated $\log$-wage function $\log \left(w_{j}(n)\right)$ against years of schooling $n$ for each sector after netting out demographics, i.e.,

$$
\widehat{\log \left(w_{i j t}\right)}=\hat{\beta}_{d j}+\hat{\beta}_{n j} n_{i j t}+\hat{\beta}_{c j} c_{i j t}
$$

As we can see from Figure 2, the returns to schooling are initially steeper in the service sectors than in agriculture and subsequently similar. Moreover, the returns are similar in industry and agriculture, but industry has a larger intercept.

Table 3 reports the gaps in human capital and residual wages implied by our estimates of the sectoral Mincer returns to schooling. Comparing Tables 2 and 3, we can see that the human capital gaps computed with sector-specific Mincer returns are much larger than those computed with aggregate Mincer returns, and correspondingly the residual wage gaps are much smaller. In particular, the residual wage gap in industry declines from more than $41 \%$ to $21 \%$. It turns out that most of the remaining residual wage gap of $21 \%$ is due to the sizable residual wage gaps in construction and especially mining, which presumably compensate workers for more physically demanding work and larger health risks in these subsectors. With sector-specific Mincer returns the residual wage gaps between the service sectors and agriculture are now negative. This means that the average wages per efficiency unit are lower in the service sectors than in agriculture, which is likely to reflect that working in agriculture is more physically demanding and has larger health risks than working in services. Given these considerations, we interpret our findings to imply that human capital gaps measured with sector-specific Mincer returns account for most of the wage gaps between the non-agricultural sectors and agriculture. 
Table 3: Gaps in Human Capital and Residual Wages with Sectorspecific Rates of Return (U.S. 1980-2015)

\begin{tabular}{lccc}
\hline & Raw wages & Hum. cap. & Res. wages \\
\hline Non-agriculture & 1.52 & 1.52 & 1.06 \\
1. Industry & 1.65 & 1.38 & 1.21 \\
2. Services & 1.48 & 1.73 & 0.91 \\
2.1 Unskilled services & 1.25 & 1.35 & 0.98 \\
2.2 Skilled services & 1.63 & 2.09 & 0.86 \\
\hline
\end{tabular}

${ }^{a}$ A gap is the ratio of the value relative to its value in agriculture.

\subsection{Discussion}

A possible concern with what we have done so far is that our findings may be explained in large part by the high percentage of immigrants working in agriculture. In Online Appendix A.2, we re-compute wage and human capital gaps for natives born in the U.S. only using the monthly CPS files from 1994 onward (the variable on citizenship is not available before 1994). As one might expect, the gaps in raw and adjusted wages are somewhat smaller for natives, suggesting that part of the low wages in agriculture are explained by the presence of a high proportion of immigrants. But it is still the case that using aggregate Mincer returns leaves large residual wage gaps in industry and skilled services to be explained. Moreover, it turns out that using sector-specific Mincer returns accounts for more of the wage gaps for natives than for all workers. The reason for this is that the sectoral gaps in the returns to schooling are actually slightly larger for natives than for all workers. In other words, if anything, our conclusion would be even stronger for natives than for all workers.

A second possible concern with what we have done so far is that agricultural wages may be depressed by an unusually high incidence of seasonal or part-time labor. Indeed, it is true in the data that agricultural labor is more cyclical than other sectors: the number of workers and hours per worker both rise in the summer while hourly wages fall. However, in terms of wages, these seasonal effects remain small: over the year, agricultural wages differ by at most $5 \%$ from the average agricultural wage. This suggests that cyclical variation in the agricultural labor force is not likely to account for much of our wage gaps.

A third possible concern with what we have done so far is that our way of obtaining human capital eliminates wage gaps by construction. One may think that since we start with a sectoral wage gap and then use sectoral returns to schooling, this "must" account for the sectoral wage gap. We stress that this is not the case and that there is nothing in our methodology that forces human capital to account for wage gaps. In particular, 
there is nothing that prevents us from estimating that the return to schooling is higher in agriculture than non-agriculture and concluding that the human capital gap is smaller and the residual wage gap is larger than with the traditional methodology. This possibility is not academic. In Online Appendix A.3 we provide a falsification test by looking at the union wage gap that we do not expect to be explained at all by human capital or selection. We show that union workers earn higher wages but earn lower returns to schooling than non-union workers. Thus, our method leads to a residual wage gap between union and non-union workers that is larger than the raw wage gap.

There are two natural interpretations for our finding that sectoral Mincer returns are larger in non-agriculture. The "sectoral hypothesis" attributes the differences in Mincer returns to sectoral technologies: schooling generates less human capital for workers who choose agriculture. The "selection hypothesis" attributes the differences in Mincer returns to workers: workers sort according to their unobserved ability while schooling generates the same human capital in each sector. As a result, the non-agricultural sectors are more human capital-intensive and have higher Mincer returns than agriculture.

\section{Model}

We now develop a simple model of selection that is consistent with our findings for the U.S. Our model adds two new features to the standard multi-sector model that has been employed in the macro-development literature: the returns to human capital may differ across sectors; workers are heterogenous with respect to observed and unobserved human capital. The model serves to derive sharp implications of the two natural interpretations of our findings that we can confront with the data. The model could also be used to provide an upper bound on the effects of barriers to moving labor on aggregate GDP per worker.

\subsection{Environment}

There is one period and a continuum of measure one of individuals. Each individual is endowed with one unit of time, an innate ability $x \in[0, \bar{x}]$ and a number of years of schooling $n \in[0, \bar{n}]$. For analytical convenience, we do not restrict $n$ to be an integer but allow it to be a real number. As in the empirical part above, $n$ includes college years, and so an individual with $n$ years of schooling has $c(n) \equiv \max \{0, n-12\}$ years of college. $\Omega$ denotes the set of individual types $(x, n)$ and $\mu(x, n)$ denotes the density function over individual types. We assume that the density function is positive for each $(x, n) \in[0, \bar{x}] \times[0, \bar{n}]$. 
There are four sectors which produce different value added and are indexed by $j \in J \equiv$ $\{a, i, u, s\}$, which stand for agriculture, industry, unskilled services, and skilled services. Individual preference over the value added from the different sectors are represented by a CES utility function:

$$
u\left(y_{a}, y_{i}, y_{u}, y_{s}\right)=\sum_{j \in J}\left(\alpha_{j} y_{j}^{\frac{\sigma-1}{\sigma}}\right)^{\frac{\sigma}{\sigma-1}}
$$

where $\alpha_{j} \in(0,1)$ are relative weights and $\sigma \in[0, \infty)$ is the elasticity of substitution between the consumption of value added from the different sectors. ${ }^{12}$ Individuals do not value leisure, implying that in equilibrium they will allocate their entire time endowment of one to work.

An individual with characteristics $(x, n)$ who works in sector $j$ has $h_{j}(x, n)$ units of human capital. $h_{j}$ is a smooth function that is non-decreasing in both of its arguments.

In each sector, value added is produced according to a production function:

$$
Y_{j}=H_{j}^{\theta_{j}}
$$

where $H_{j}$ denotes total human capital (or efficiency units of labor) in sector $j$ and $\theta_{j}$ is the labor share in sector $j$. For future reference, we denote by $\nu_{j}(x, n)$ an indicator function that equal one if individual $(x, n)$ works in sector $j$ and zero otherwise.

The development literature considers barriers that prevent the free movement of labor from agriculture to the other sectors and distort the efficient allocation of labor between the sectors. A simple way of capturing the effects of such barriers on the allocation of labor is by assuming that there are taxes $\tau_{j}$ on the wages in the non-agricultural sectors $j=\{i, u, s\}$ that get rebated through a lump-sum transfer $T$ to all individuals. This is similar to how Restuccia et al. (2008) modeled barriers in the case of agriculture and non-agriculture. ${ }^{13}$

\footnotetext{
${ }^{12}$ Herrendorf et al. (2013) show that the demand system implied by a CES with low elasticity of substitution matches the postwar U.S. data on agriculture, industry, and services reasonably well if one takes the view that sectoral consumption is sectoral value added consumed. We take this view here.

${ }^{13} \mathrm{~A}$ different way of modeling barriers would be to assume that $\tau_{j}$ is only paid by workers who newly enter the sector ("outsiders") but not by workers who are already working in sector $j$ ("insiders"). While that would not affect the key equilibrium properties, it would complicate the analysis somewhat by adding an additional state variable (the set of insiders in each sector). It would also change one feature of the equilibrium: insiders would strictly prefer to work in their sector. We will see below that this interpretation is sometimes useful when we think about specific features of the data.
} 


\subsection{Equilibrium definition}

A competitive equilibrium is goods prices, rental rates for effective labor units, profits, tax rates, choices of consumption and sector, and output and efficiency units of labor, $\left\{p_{j}, w_{j}, \Pi_{j}, \tau_{j},\left(y_{j}, \nu_{j}\right)(x, n), Y_{j}, H_{j}\right\}_{j \in J}$, in each sector such that:

- $\left\{\left(y_{j}, \nu_{j}\right)(x, n)\right\}_{j \in J}$ solve the individual problem:

$$
\max _{\left\{y_{j}, \nu_{j}\right\}} u\left(y_{a}, y_{i}, y_{u}, y_{s}\right) \quad \text { s.t. } \quad \sum_{j=1}^{J} p_{j} y_{j}=\sum_{j=1}^{J}\left[\left(1-\tau_{j}\right) w_{j} h_{j}(x, n) \nu_{j}+\Pi_{j}\right]+T
$$

- $\left(Y_{j}, H_{j}\right)$ solve the firm problem in sector $j$ :

$$
\max _{Y_{j}, H_{j}} \Pi_{j}=p_{j} Y_{j}-w_{j} H_{j} \quad \text { s.t. } \quad Y_{j}=H_{j}
$$

- markets clear for all $j \in J$ :

$$
\begin{aligned}
Y_{j} & =\int_{(x, n) \in \Omega} y_{j}(x, n) d \mu(x, n) \\
H_{j} & =\int_{(x, n) \in \Omega} h_{j}(x, n) \nu_{j}(x, n) d \mu(x, n)
\end{aligned}
$$

- the government budget is balanced:

$$
T=\sum_{j=2}^{J} \tau_{j} \int_{(x, n) \in \Omega} w_{j} h_{j}(x, n) \nu_{j}(x, n) d \mu(x, n)
$$

One might be tempted to start solving this model by requiring that in equilibrium the rental rates of human capital are equalized across sectors, $w_{j}=w_{j^{\prime}}$. For two reasons, this is not an equilibrium property of our model: since $h_{j}(x, n) \neq h_{j^{\prime}}(x, n)$, wages have to adjust such that the labor market clears and the "right" number of efficiency units of labor are allocated to each sector; wages in sectors $j=\{i, u, s\}$ are taxed in our model, so $w_{j}$ may exceed $w_{a}$ even if the net wages are equalized across sectors.

\subsection{Equilibrium sorting}

We now explore whether sorting according to individual characteristics can lead to an equilibrium with the broad features that we have found in the data: (i) industry has a higher 
intercept than agriculture and a similar rate of return to schooling; (ii) unskilled services have a somewhat lower intercept and a somewhat higher rate of return than agriculture; (iii) skilled services have a lower intercept and a higher rate of return than agriculture.

To make our model tractable, we need to impose additional restrictions. Given the empirical findings from subsection 3.4, we make the following assumption:

$$
h_{j}(x, n)=\exp \left(\gamma_{j} x n+\beta_{c} c(n)\right)
$$

where $\gamma_{j}$ is the rate of return to the product of total years of schooling, $s$, and innate ability, $x$, and $\beta_{c}$ is the rate of return to years of college $c(n) \equiv \max \{0, n-12\}$. This functional form has three key features. First, for an individual with zero schooling, human capital equals one in all sectors. That is the standard restriction imposed in the humancapital literature. Second, the Mincer return to schooling depends on the product of the sector-specific technology parameter $\gamma_{j}$ and the person-specific innate ability $x$. Third, the additional return to college is independent of the sector and the innate ability. This assumption is motivated by the evidence summarized in Figure 2. Although the returns to college are not literally the same, the differences are much smaller than those among the returns to schooling. In addition, since there are many more years of schooling before college than years of college, only the differences among the returns to schooling are quantitatively of first-order importance here. ${ }^{14}$ We therefore buy tractability by abstracting from the relatively small sectoral differences among the returns to college.

We start characterizing the equilibrium of our model by deriving a series of properties that it has to satisfy if the equilibrium relationships implied by the model are to match the empirical findings. We then specify conditions on the environment under which these properties are met and an equilibrium exists that is consistent with the empirical findings. For what follows, it is useful to define the average Mincer returns to years of schooling $n$ in sector $j$ that is implied by our model and the sectoral average wages per worker:

$$
\begin{aligned}
\beta_{n j} & \equiv \frac{\gamma_{j} \int \nu_{j}(x, n) x \mu(d x, n)}{\int \nu_{j}(x, n) \mu(d x, n)} \\
W_{j} & \equiv \frac{w_{j} \int h_{j}(x, n) \nu_{j}(x, n) d \mu(x, n)}{\int \nu_{j}(x, n) \mu(d x, n)}
\end{aligned}
$$

Lemma 1. Suppose that $\tau_{u}=\tau_{s}=0$ and there is an equilibrium such that

\footnotetext{
${ }^{14}$ Compare also the discussion in Footnote 11.
} 
- $w_{a}<w_{i}$

- for all $n \in(0, \bar{n})$ there are individuals with $n$ years of schooling in each sector

- the average Mincer returns satisfy

$$
\beta_{n a}=\beta_{n i}
$$

In the equilibrium, it must be the case that

- $\gamma_{a}=\gamma_{i}$

- $\tau_{i}=\left(w_{i}-w_{a}\right) / w_{i}$

- all individuals are indifferent between agriculture and industry

Proof: See Appendix 1.

Lemma 1 says that viewed through the lens of our model our empirical finding that the regression of log wages on years of schooling has a larger intercept in industry than in agriculture but the same slope must mean that there are barriers for entering industry. There are at least two plausible interpretations for such barriers: they may reflect the presence of labor unions which raise industry wages above the competitive ones; they may reflect a wage premium for harsher work conditions in industry and construction in general and in particular in mining. For either interpretation, it is most natural to think that $\tau_{i} w_{i}$ is actually received by the workers in industry as compensation for these conditions. Since modeling this would require us to add utility costs of working in industry to the model, we have not done this here. Since the equilibrium would not change, we hope that it is implicitly understood that this interpretation is consistent with the equilibrium derived here.

The next Lemma explores how our model views our findings for services versus agriculture:

Lemma 2. Suppose that $\tau_{u}=\tau_{s}=0$ and there is an equilibrium such that

- $w_{a}>w_{u}>w_{s}$

- for all $n \in(0, \bar{n})$ there are individuals with $n$ years of schooling in each sectors

- the slopes satisfy

$$
\beta_{n a}<\beta_{n u}<\beta_{n s}
$$


In the equilibrium, it must be the case that

- $\gamma_{a}<\gamma_{u}<\gamma_{s}$

- there are thresholds $0<\chi_{1}<\chi_{2}<\bar{x} \bar{n}$ such that individuals with $x n \in\left(0, \chi_{1}\right)$ choose agriculture or industry, individuals with $x n \in\left(\chi_{1}, \chi_{2}\right)$ choose unskilled services, and individuals with $x n \in\left(\chi_{2}, \bar{x} \bar{n}\right)$ choose skilled services.

Proof. See Appendix 2.

Lemma 2 says that viewed through the lens of our model our empirical findings must mean that human capital gets a higher rate of return in the service sectors than in agriculture. To induce individuals to choose agriculture nonetheless, the wage per efficiency unit needs to be larger in agriculture. Individuals with relatively low endowments of efficiency units will then choose agriculture, because for them the higher wage per efficiency unit in agriculture matters relatively more than the lower rate of return. Note that the sorting implied by Lemma 2 applies to the product of schooling and ability, $x n$, instead of just to schooling. Hence, in all sectors there can be individuals with a given number of years of schooling as long as those working in agriculture have lower innate ability than those working in unskilled service and those working in unskilled service have lower innate ability than those working in skilled services.

The sorting of Lemma 2 implies that the observed wages per hour in agriculture, unskilled services, and skilled services, $\left(W_{a}, W_{u}, W_{s}\right)$, behave as we have seen above:

Lemma 3. Suppose that $\tau_{u}=\tau_{s}=0$ and there is an equilibrium such that

- $w_{a}>w_{u}>w_{s}$

- for all $n \in(0, \bar{n})$ there are individuals with $n$ years of schooling in each of the sectors

- the slopes satisfy (5)

It must then be that $W_{a}<W_{u}<W_{s}$.

Proof. See Appendix 3.

It remains to show that an equilibrium with the above properties indeed exists in our model:

Proposition 1. Suppose that $\gamma_{a}=\gamma_{i}$ and $\gamma_{a}<\gamma_{u}<\gamma_{s}, \tau_{i}>0$, and $\tau_{u}=\tau_{s}=0$. Then there exists an equilibrium with the following properties:

- $w_{i}>w_{a}>w_{u}>w_{s}$ 
- $W_{i}>W_{a}$ and $W_{a}<W_{u}<W_{s}$

- for all $n \in(0, \bar{n})$ there are individuals with $n$ years of schooling in each sector

- the slopes satisfy the conditions specified in (4) and (5).

Proof. See Appendix 4

In sum, we have found that viewed through the lens of a simple multi-sector model, our empirical findings imply that the sectoral technologies are the same in agriculture and industry, that there are barriers to entry into industry, and that the rate of return on human capital is largest in skilled services, second largest in unskilled services, and smallest in agriculture and industry.

An obvious next question to ask is, what does this imply about the importance of the sectoral view versus the selection view for explaining our empirical findings. The facts that the difference in the wages per efficiency unit between skilled services and agriculture is rather small and that the years of schooling at which the log-wage functions of the two service sectors cross that of agriculture is as low as five years suggest that for unskilled and skilled services the sectoral view is not very important. In terms of applying this insight, we face the problem that we do not observe $\tau_{u}$ and $\tau_{s}$. If they were large (which is possible but unlikely to be true in the U.S. economy), then we could have large differences in the net wage per efficiency unit, $\left(1-\tau_{j}\right) w_{j}$, and in the sectoral rates of return, $\gamma_{j}$. To further investigate these possibilities, we therefore turn to new evidence now from the experience of individuals who switched sector in the U.S.

Table 4: Percentage differences between wage gaps in matched and unmatched samples (U.S. 1980-2015)

\begin{tabular}{lccc}
\hline & Raw & Adjusted & Residual \\
\hline Industry & 0.8 & 0.5 & 3.8 \\
Unskilled services & 2.8 & 2.3 & 4.3 \\
Skilled services & 0.2 & 0.7 & 0.3
\end{tabular}

${ }^{a}$ The residual wage gaps are estimated with sector-specific returns.

\section{$5 \quad$ Wage Changes for Switchers in the U.S.}

\subsection{Switchers in the CPS}

We now study the wage patterns of workers who switch sectors ("switchers"). We will find that switchers experience wage gains that are small relative to the initial wage gaps. We 


\section{Figure 3: Sectoral Return to Schooling}

\section{a) Monthly CPS}

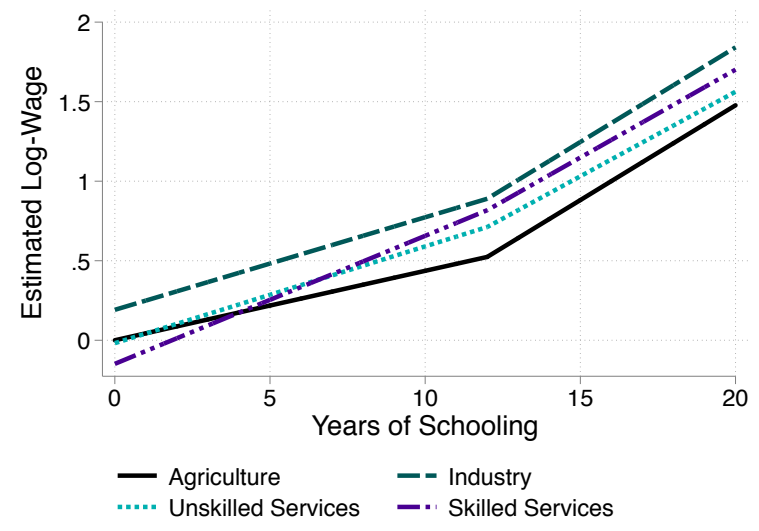

b) Matched CPS

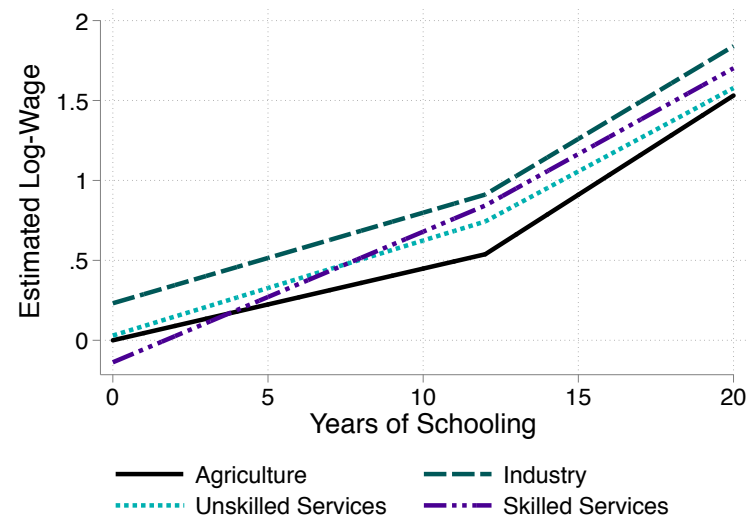

will argue that this indicates that the wage differences are mostly intrinsic to the workers, which supports the conclusions derived so far. To make this argument convincing, we need to address the possibility that the wage gains from switching differ across workers. Selection then implies that the observed wage gains from switching are likely to be an overestimate of the gains that would result if a representative worker switched. While that is true, selection also implies that the observed wage gains from switching can be used as an upper bound of the wage gains that would obtain if a representative worker switched. The fact that we will find that the observed wage gains from switching are relatively small then means that we draw our conclusion that the wage differences are mostly intrinsic to the workers.

Our ideal data set has a panel dimension so that we can compare the wages of the same worker before and after switching industries. Our ideal data set also has a large sample so that we can observe a sufficient number of switchers. The only data set that we are aware 
Table 5: Wage Changes of Switchers versus Adjusted Wage Gaps

\begin{tabular}{lccc}
\hline & Observations & Wage Changes & Adjusted wage gap \\
\hline Agriculture to industry & 1,721 & 1.11 & 1.67 \\
Agriculture to unskilled services & 1,822 & 1.05 & 1.35 \\
Agriculture to skilled services & 1,432 & 1.11 & 1.81 \\
Industry to agriculture & 1,648 & 0.86 & 0.60 \\
Industry to unskilled services & 20,771 & 0.94 & 0.81 \\
Industry to skilled services & 20,074 & 0.98 & 1.08 \\
Unskilled services to agriculture & 1,845 & 0.94 & 0.74 \\
Unskilled services to industry & 22,100 & 1.07 & 1.24 \\
Unskilled to skilled services & 31,297 & 1.07 & 1.34 \\
Skilled services to agriculture & 1,298 & 0.95 & 0.55 \\
Skilled services to industry & 18,916 & 1.03 & 0.93 \\
Skilled to unskilled services & 26,562 & 0.95 & 0.75 \\
\hline
\end{tabular}

Wage changes refer to the average annual wages of switchers relative to workers who remain in the same sector). Wage changes are statistically different from zero, and wage changes of switchers are statistically different from those who stay in the same industry.

of that satisfies these requirements is the CPS. The CPS provides the sample size that we need and includes a short panel structure: households are in the CPS for four months, then out for eight months before returning for four more months. We focus on matching the fourth month of each spell, when extra data are collected (the so-called "outgoing rotation groups"). The resulting two observations are separated by one year and allow us to study the changes in wages for workers who switch sectors in the intervening year.

Matching workers over time in the CPS is known to be challenging because the CPS samples dwellings based on address and surveys whoever lives in that dwelling. In some cases, the occupants in that dwelling differ over time. In principle the CPS denotes when a household changes in a dwelling, but unfortunately the household and person identifiers are known to have frequent coding errors. Fortunately, we can follow a well-established procedure for dealing with these issues (Madrian and Lefgren, 1999, 2000), which matches all persons who share the same dwelling, household, and person identifiers and then checks whether the responses are logically consistent across time within a match. A tradeoff arises in doing this: if one checks more variables and/or requires stricter agreement over time, then one not only excludes more false matches, but also more valid ones for which a code is misreported. We adopt a fairly strict check by requiring that age, sex, and race all agree, 
which allows us to match about two thirds of all participants in the CPS. ${ }^{15}$

Before analyzing the data, we need to make certain that the matched workers do not differ in obvious ways from the unmatched workers. We focus on the two moments that are of most interest to our analysis: the raw wage gap and the returns to schooling. Table 4 shows that the raw wage gaps in the monthly CPS and in the matched CPS agree closely as they should. To check whether the sectoral returns to schooling are similar for the matched and unmatched data sets, we estimate the same equation for each data set and plot the resulting wage as a function of schooling profiles. Figure 3 shows that the two profiles are again similar. It is reassuring that the matching process yields a data set with similar features as the baseline data.

We start analyzing switchers by reporting several descriptive statistics about them. First, the probability of switching falls a lot with age. It's about $20 \%$ annually at age 20, falls to $10 \%$ annually by age 30 , then slowly declines to $5 \%$ at age 70 (in 4 -sector terms). One reason for this patterns is that the wage change at switching falls over the life cycle. Relative to a worker who switches at age 16, workers who switch at age 25 will lose $3 \%$ more/gain 3\% less; at age 30 the figure is $4 \%$; at age 40 the figure is $5 \%$ and at age 50 $6 \%$. This suggests that workers are sampling at the beginning of their work life (lots of turnover, little sector-specific human capital or wage loss) but being shocked at the end of life (little turnover, more sector-specific human capita or wage loss). Nonetheless, our results are pretty similar if we restrict our analysis to only those who switch when young (less than 35 years old).

We now turn to analyzing the experiences of switchers and non-switchers in the matched CPS. We focus on the determinants of the annual changes in wages, that is, we want to understand for worker $i$ who works in sectors $j$ and $j^{\prime}$ in periods $t-1$ and $t$ the determinants of $\Delta \log \left(w_{i j j^{\prime} t}\right) \equiv \log \left(w_{i j t}\right)-\log \left(w_{i j^{\prime} t-1}\right)$ where $j, j^{\prime} \in\{a, i, u, s\}$. We run the following regression:

$$
\Delta \log \left(w_{i j j^{\prime} t}\right)=\beta_{d j j^{\prime}} d_{j j^{\prime}}+\beta_{d t} d_{t}+\varepsilon_{i j j^{\prime} t}
$$

where $j j^{\prime}$ denotes a sector pair; for example, $j j^{\prime}=a, a$ denotes workers who stay in agriculture and $j j^{\prime}=a, u$ denotes workers who switch from agriculture to unskilled services. The idea of this regression is to capture the mean effect of switching sector versus staying

\footnotetext{
${ }^{15}$ Agreement here means that: the gender is the same; the race report of white or non-white is the same; the age in the later period is between the same and two years older than the age in the earlier period (since the CPS is not necessarily asked on the exact same date of the month each time, this is the strictest agreement on age that one can check).
} 
in the same sector, controlling for trend wage growth with $d_{t}$. Table 5 shows the resulting estimates relative to the average annual wage growth of workers who remain in sector $j$. The key finding of this table is that wage gains are quite small relative to the raw wage gaps. Specifically, switching between sectors that have sizable raw wage gaps to begin with closes at most a quarter of the raw wage gaps. Moreover, the wage changes go in the right directions: leaving agriculture increases wages and entering agriculture decreases wages.

The results from switchers suggest that at most a quarter of the raw wage gaps are due to the sectoral view and at least three quarters are due to the selection view. In other words, we again arrive at the conclusion that most of the wage gaps represent selection of workers of different types. ${ }^{16}$

\subsection{Switchers in the PSID}

Our analysis above of switchers in the CPS has two limitations: the CPS will lose individuals who change residence; the CPS only observes individuals one year after a switch. In this subsection, we use the Panel Survey of Income Dynamics (PSID) to provide evidence that these limitations are unlikely to drive our results. The PSID is suitable for this purpose because it is a true panel survey that follows workers over many years irrespective of whether they move residence. In contrast, the CPS is a cross-sectional survey with a short panel element, which loses workers when they move residence. Another advantage of the PSID, which was stressed by Kambourov and Manovskii (2008), is that, as part of a harmonization project by the PSID in 1996, many of the occupation and industry codes in the PSID were systematically recoded from the original textual responses to the Census occupation and industry schemes from 1970. This reduces the chances of artificial sector switches arising from changes in coding procedures over time.

It is important to recognize that despite these advantages over the CPS, the PSID also has serious limitations that make it a useful complement to rather than a good substitute for the CPS. The main limitation of the PSID is sample size: we observe an order of magnitude fewer industry switches in the PSID than in the CPS. A second limitation of the PSID is that it is designed as a survey of heads of households, with only limited collection of labor market information about other members of the household. This is an issue if male heads

\footnotetext{
${ }^{16}$ We have also studied switchers for the fifteen-sector case. To ensure a sufficient sample size, we have focused our attention on categories for which switches are frequent and the adjusted wage gap is large. For the 128 (out of 210) $(i, j)$ pairs with at least 100 switchers and a 10\% adjusted wage gap, the median pair has a gain to switching that is just $18 \%$ of the adjusted wage gap, in line with the numbers for the four-sector case. To give a sense of the range, the 10 th percentile has a $9 \%$ loss and the 90 th percentile a $43 \%$ gain of the adjusted gap.
} 
of household are not be representative of the total labor force.

We focus on the period 1968-1997. The PSID switched to biannual data collection from 1997 onward, making it more difficult to analyze workers who switch industries at some point in a two-year period. We limit attention to the subsample of male heads of household who work for wages, were less than 70 years old, and had 0-50 years of potential experience in each period. We measure the wage as the hourly wage in periods $t$ and $t^{\prime}$ for workers who work in sectors $j$ and $j^{\prime}$. As with the CPS analysis, we exclude workers who report switching industries but not occupations in order to minimize the chances of analyzing miscoded switches. After doing this, we are left with a sample of 64,677 workers that are matched across one-year periods, including 5,602 who switch sectors (at a four-sector level).

We construct an adjusted wage gap by regressing log-wages on state, year, and sector dummies. We then estimate again Equation (6) for workers who switch sectors. The results are reported in Table 16 in Online Appendix B.3. The patterns for adjusted wage gaps are similar to the CPS, with agriculture paying by far the lowest wage, unskilled services paying the next lowest, and skilled services and industry paying the highest. Although we observe many fewer switchers than in the CPS, we still find very similar patterns for the wage changes of switchers: they generally go in the right direction, but are of much smaller magnitude than the adjusted wage gap between sectors.

We also explore the long-term wage changes of switchers. To do so, we start with a sample of workers who switch sectors between $t$ and $t+1$. We then restrict attention to the subsample of employed wage workers who were household heads with valid experience and age at time $t$ and $t+2$. By examining $t+2$, we can measure their wage change $1-2$ years after switching, rather than 0-1 years. Of course, our sample size falls further for this case, to roughly one-half of the sample size for looking at one-year switches. Table 16 in Online Appendix A.3 again reports the results. Wages show modest further movement in the direction of the raw wage gap, but the additional change between year one and two is still small relative to the total wage gap. We also explored wage changes over even longer periods, but the sample size drops too quickly to say anything definitive. In particular, we have very small samples for switches between agriculture and the non-agricultural sectors, which are precisely the areas with large adjusted wage gaps.

Not withstanding these limitations of the PSID, the PSID and the CPS agree on the broad facts of wage changes for switchers. 


\subsection{Switchers in other countries}

Don't forget to cite: Alvarez (2015); Hicks et al. (2017).

Two recent studies, Beegle et al. (2011) and Swiecki (2014), provide useful complements to our empirical analysis of switchers. These authors study switchers in Indonesia and Tanzania. They follow workers over longer periods (instead of one year), even if they move houses. Despite the quite different setting and design, their findings broadly agree with ours: workers who switch sectors experience income (or consumption) changes in the expected direction of between one third and one half of the total wage gap. Workers who switch sectors and locations experience larger changes, in some cases exceeding one half of the total gap. Such changes obviously conflate location premiums with sector premiums.

\section{Wages and Structural Transformation}

So far, we have analyzed the determinants of wage gaps in the U.S. since 1980. There are large sectoral wage gaps that can be explained by sectoral gaps in human capital, but only if one uses sectoral returns to schooling when constructing human capital stocks. We limited our attention to the recent U.S. so that we could use data on workers who switch sectors as well as theory to establish that this adjustment is logically consistent, in the sense that it captures the selection of different types of workers into the different sectors.

Now we turn our attention to the implications of our findings for structural transformation. In order to do so, we need data on wages, education, and industry for countries in various stages of the process of structural transformation. Here, we focus on two: we follow the U.S. as far back in time as we can, from 1940-2010, and we construct a panel of countries at various levels of development. We will ask three questions: Are there wage gaps along the same lines as in the U.S.? Do the returns to schooling vary in the same systematic way as in the U.S.? Do the adjusted wage gaps vary in the same systematic way as in the U.S.? Doing this is crucial for thinking about the questions in the introduction: Is ST efficient or not? Are there barriers that lead to wage gaps and prevent structural transformation from taking place? We will establish that the previous findings mostly carry over to our panel of countries. We will not find evidence for large barriers to the reallocation of labor between agriculture and the other sectors. 


\subsection{Data}

We use census data from IPUMS for the U.S. during 1940-2010 and from IPUMS International for a panel of countries, (Minnesota Population Center, 2014). These data are nationally representative and the IPUMS team has put forth a great deal of effort to harmonize variables such as education and industry that are critical for our analysis. Table 6 reports the country-year pairs for which we have sufficient data to be able to construct wages by sector. The resulting sample of countries covers about one-third of the world population in 2010 and contains four of the five most populous countries, namely, India, US, Indonesia, Brazil. In addition to rich countries like Canada and the U.S., it comprises medium-income countries like Brazil and Mexico and low-income countries like India and Indonesia. ${ }^{17}$ The standard development facts hold in our sample of countries: the crosscountry variation in GDP per capita is about 20; the largest productivity gap between non-agriculture and agriculture is about four; the largest employment share in agriculture is almost $2 / 3$.

\section{Table 6: Country-year Pairs in Our Sample}

\begin{tabular}{ll}
\hline Brazil $(1991,2000,2010)$ & Canada $(1971,1981,1991,2001)$ \\
Dominican Republic $(1981)$ & India $(1983,1987,1993,1999,2004)$ \\
Indonesia $(1976,1995)$ & Israel $(1995)$ \\
Jamaica $(1982,1991,2001)$ & Mexico $(1990,2000,2010)$ \\
Panama $(1970,1990,2000,2010)$ & Puerto Rico $(1990,2000)$ \\
US $(1940,1950,1960,1970,1980,1990,2000,2005,2010)$ & Uruguay $(2006)$ \\
Venezuela $(1981,1990,2001)$ & \\
\hline
\end{tabular}

Figure 4 plots the employment shares of the four sectors against GDP per capita in 2005 international dollars. Panel a) refers to the cross-country shares and Panel b) to the U.S. shares over time. We plot the U.S. data points separately in Panel b) although they are also included in Panel a). This is not supposed to provide additional information but to highlight what happens to the U.S. time series. The main point of these pictures is that our countries exhibit the standard patterns of the process of structural transformation as summarized by Herrendorf et al. (2014). The agricultural labor share has declined from as high as 60 percent to a few percentage points across countries. The pattern for industry shows the hump shape that one would expect, while the service share is increasing. By

\footnotetext{
${ }^{17}$ Unfortunately, our sample does not contain African countries because IPUMS does not report the census information for them that is required to calculate sectoral wages.
} 
disaggregating services into skilled and unskilled services we are also able to capture an additional component of structural transformation, namely that for middle-income and high-income countries skilled services grow with GDP per capita whereas unskilled services are unrelated to GDP per capita. This is consistent with the theory of Buera and Kaboski (2012).

\section{Figure 4: Structural Transformation}

\section{a) Panel of Countries}
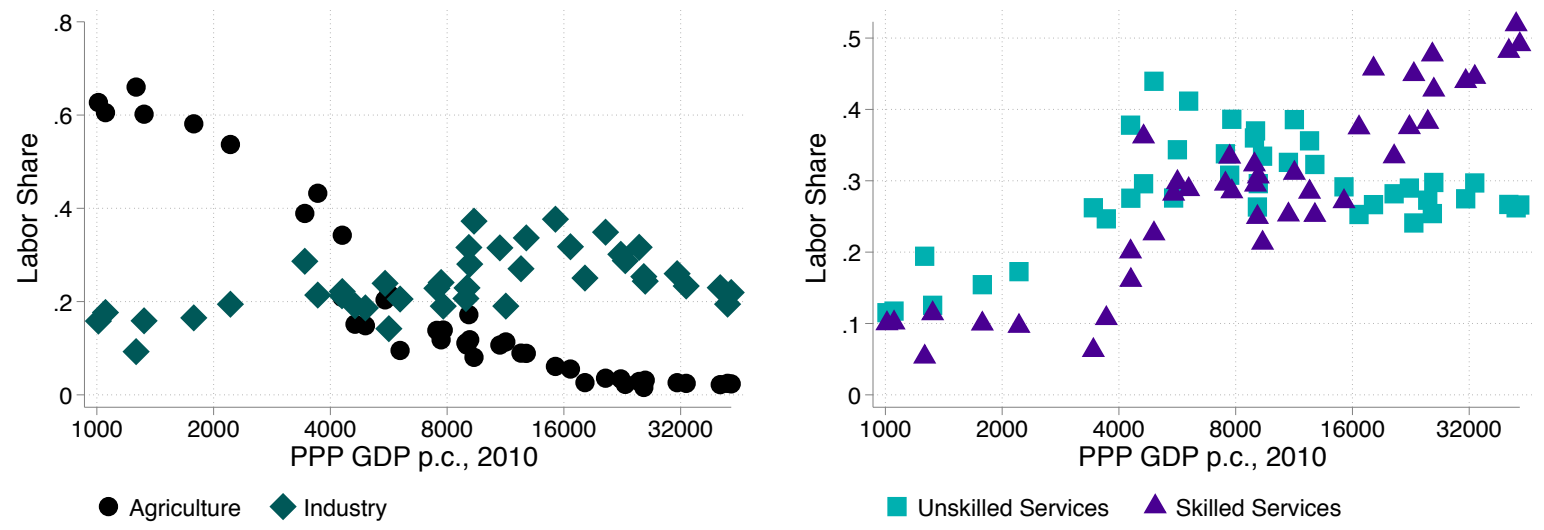

b) US Time Series

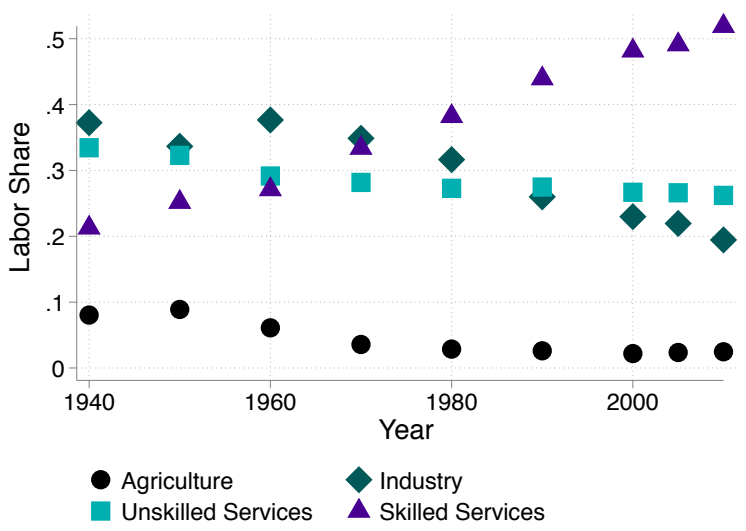

\subsection{Wage gaps across countries}

We now turn to examining wage gaps. We construct a sample of wage workers along the same lines as before: we use only information from individuals for who we have valid information for our key variables: sex, education, employment by sector and so on. Since in poor countries many children work full time, we lower the age bar to 10 years or older, when such children are included in the data. We again exclude self-employed because there 
is no reliable wage information for them. One might be worried that this means that our sample does not contain sufficiently many wage workers to be able to calculate statistically meaningful average wages. However, we find that wage workers are more common in agriculture in our sample than is commonly supposed. For the median country, 42 percent of the agricultural labor force works for wages; the range is wide, from 15 to 73 percent, but the countries at the low end (particularly Indonesia) have such large agricultural labor forces that we have a large number of agricultural wage workers.

We start by examining the raw wage gaps Table 7 reports the gaps between the average wages in the non-agricultural sectors and agriculture. We again find that there are sizable wage gaps: the average wages in the non-agricultural sectors are between two and five times larger than in agriculture, with the smallest wage gap in unskilled services and the largest in skilled services. Moreover, the median gaps are quite comparable to the recent U.S. Not surprisingly, however, there now is substantial dispersion. Table 7 also shows that, different from the U.S., controlling for geography and gender tends to close sizable parts of the raw wage gaps, implying that in our international sample the adjusted wage gaps are smaller than the raw wage gaps.

Next we ask whether these gaps are associated with corresponding differences in sectoral returns to schooling. Figure 5 shows the returns to schooling by sector during the process of structural transformation. Although there is some heterogeneity across countries, we can see that skilled services consistently offers a very high return, while agriculture offers a very low return. This fact already suggests that accounting for differences in returns to schooling will help close the wage gaps. Further, the gaps are generally large in the panel of countries and in the earlier years of the U.S., which suggests that accounting for differences in returns to schooling will play an even larger role in closing wage gaps here.

Finally we explore how far we can close the adjusted wage gaps with corrections for human capital differences. Table 7 shows that adjusting for human capital differences in the same way as before again closes most of the wage gaps: Specifically, our preferred human capital correction with sector-specific returns closes the median wage gap from 1.75 to 1.39 in industry and from 1.86 to 1.11 in services. The finding that the residual wage gap is considerably larger in industry than in services is similar as for the recent U.S. The other patterns are also similar: the service sector has smaller residual wage gaps with agriculture than industry. Figures 6 visualize this. The $\mathrm{x}$-axis represents the raw gaps described in Table 7. Along the y-axis we show the successive effects of making the same adjustments that we implemented for the U.S. before. The figure clearly brings out the importance of adjusting for human capital, using both years of schooling and the sectoral return to 
Table 7: Wage Gaps across Countries

\begin{tabular}{|c|c|c|c|}
\hline & $10^{\text {th }}$ Pctl. & Med. & $90^{\text {th }}$ Pctl. \\
\hline \multicolumn{4}{|l|}{ Non-Agriculture } \\
\hline Raw & 1.51 & 1.80 & 2.71 \\
\hline Adjusted gender and geography & 1.50 & 1.69 & 2.27 \\
\hline Residual aggregate human capital & 1.23 & 1.39 & 1.72 \\
\hline Residual sector-specific human capital & 1.05 & 1.24 & 1.57 \\
\hline \multicolumn{4}{|l|}{ 1. Industry } \\
\hline Raw & 1.49 & 1.77 & 2.62 \\
\hline Adjusted gender and geography & 1.41 & 1.66 & 1.91 \\
\hline Residual aggregate human capital & 1.24 & 1.45 & 1.76 \\
\hline Residual sector-specific human capital & 1.19 & 1.42 & 1.88 \\
\hline \multicolumn{4}{|l|}{ 2. Services } \\
\hline Raw & 1.51 & 1.88 & 2.91 \\
\hline Adjusted gender and geography & 1.53 & 1.78 & 2.65 \\
\hline Residual aggregate human capital & 1.22 & 1.37 & 1.82 \\
\hline Residual sector-specific human capital & 0.96 & 1.12 & 1.42 \\
\hline \multicolumn{4}{|l|}{ 2.1 Unskilled services } \\
\hline Raw & 1.21 & 1.52 & 2.29 \\
\hline Adjusted gender and geography & 1.19 & 1.45 & 1.94 \\
\hline Residual aggregate human capital & 1.11 & 1.26 & 1.57 \\
\hline Residual sector-specific human capital & 0.98 & 1.20 & 1.48 \\
\hline \multicolumn{4}{|l|}{2.2 Skilled services } \\
\hline Raw & 1.65 & 2.25 & 3.57 \\
\hline Adjusted gender and geography & 1.70 & 2.19 & 3.26 \\
\hline Residual aggregate human capital & 1.34 & 1.62 & 1.96 \\
\hline Residual sector-specific human capital & 1.00 & 1.19 & 1.50 \\
\hline
\end{tabular}

schooling. The figure also shows that we are able to close the majority of the raw wage gaps.

Our findings are related to the work of Young (2013), who documents for many countries that migration flows go in both directions: while on average one in five individuals born in rural areas moves to urban areas as an adult, one in four individuals born in urban areas moves to rural areas as an adult. Young develops a location model in which people sort depending on observed characteristics such as schooling and on unobserved characteristics such as skills that are acquired after leaving school. The basic idea is that if observed 


\section{Figure 5: Sectoral Returns to Schooling}

a) Panel of Countries
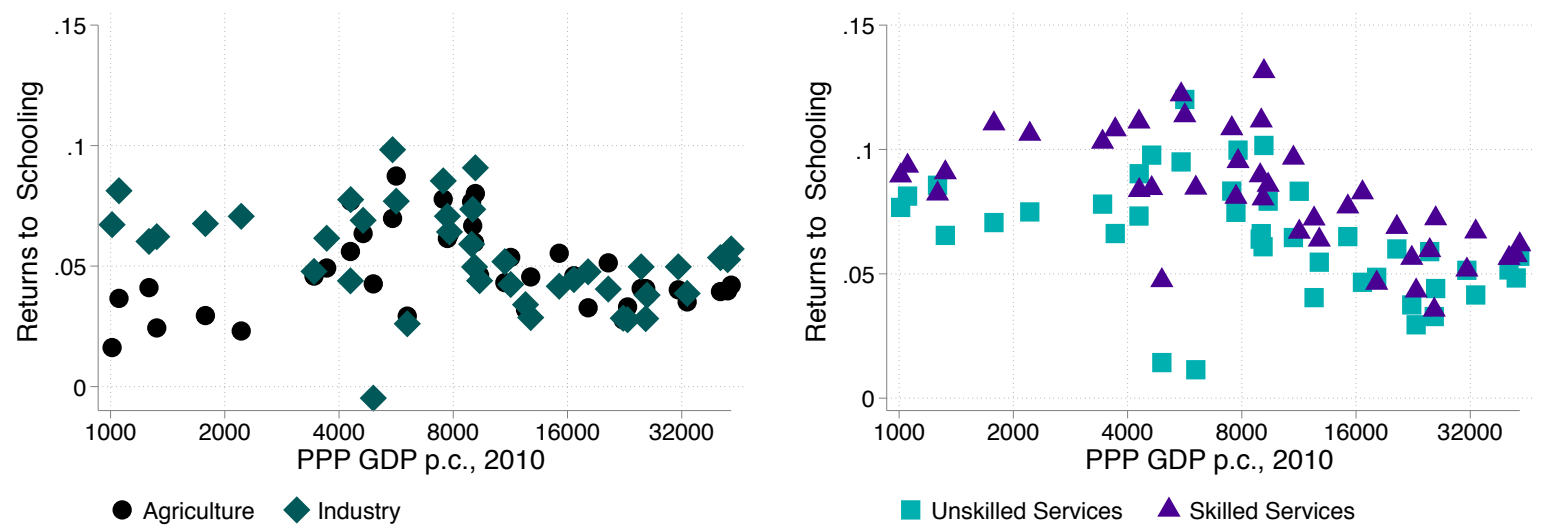

b) US Time Series

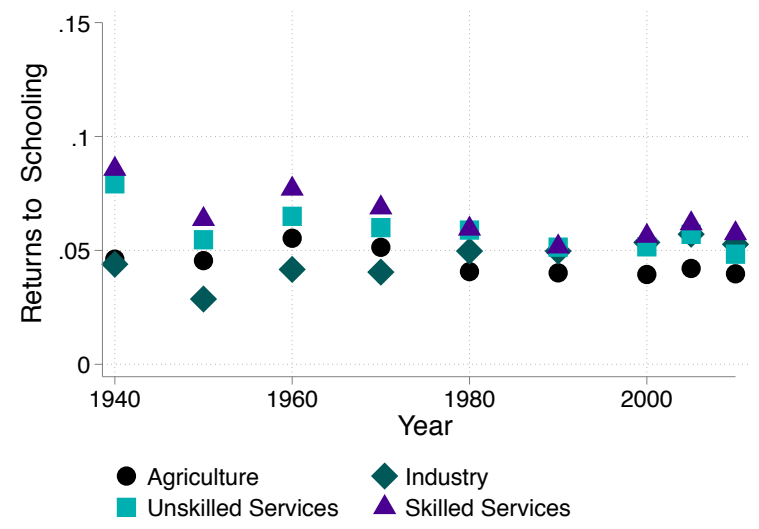

and unobserved characteristics are positively correlated and are more important as an input in production in urban areas, then sorting implies that on average individuals with higher observed and unobserved characteristics locate in urban areas and individuals with lower observed and unobserved characteristics locate in rural areas. Since our concept of human capital is broad in the sense that it includes the stocks of observed and unobserved characteristics, this prediction of Young is consistent with our finding that most of the wage gaps between the service sectors and agriculture are accounted for by the fact that workers in the service sectors have more human capital than workers in agriculture.

\subsection{Implications for barriers}

Our work for the U.S. suggested that the selection view explains most of the wage gaps. If we make the extreme assumption that the selection prevails and there are no differences 
Figure 6: Wage Gaps and Adjusted Wage Gaps

a) Panel of Countries

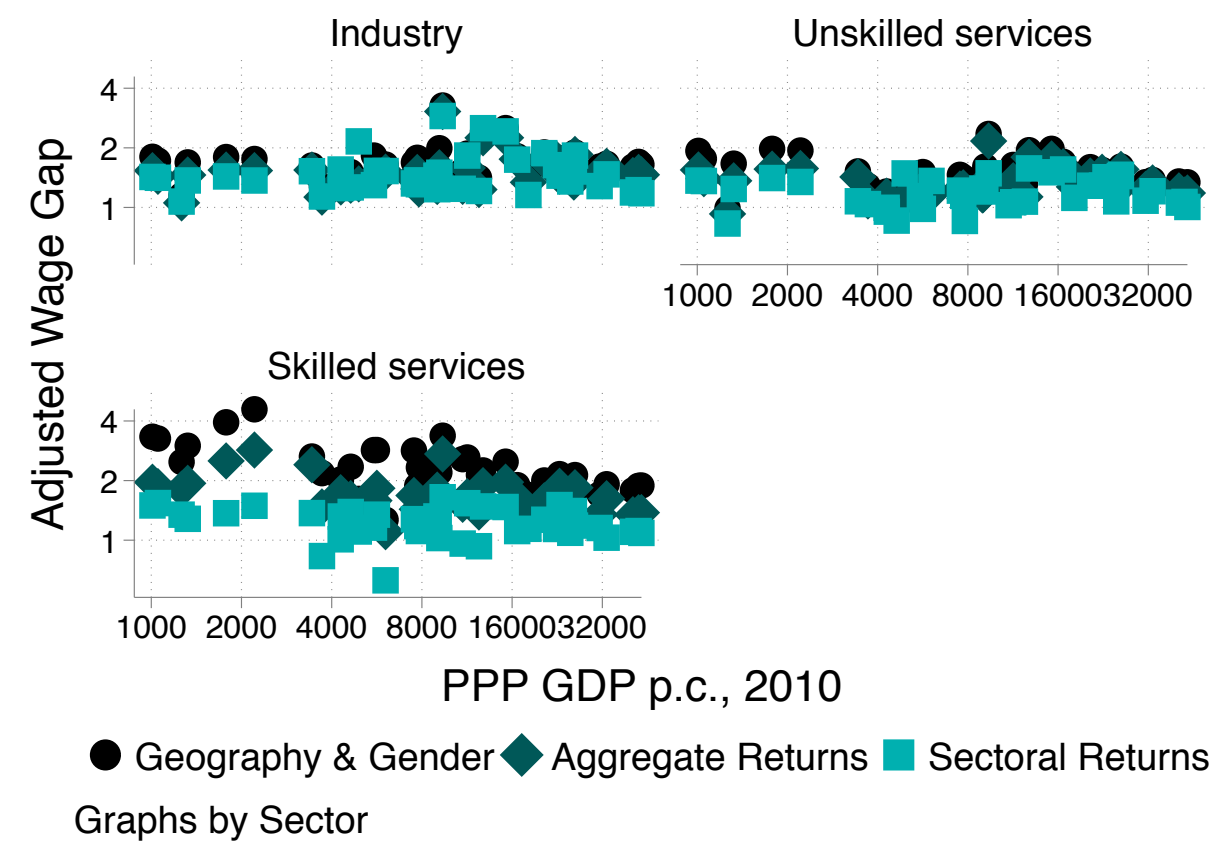

b) US Time Series

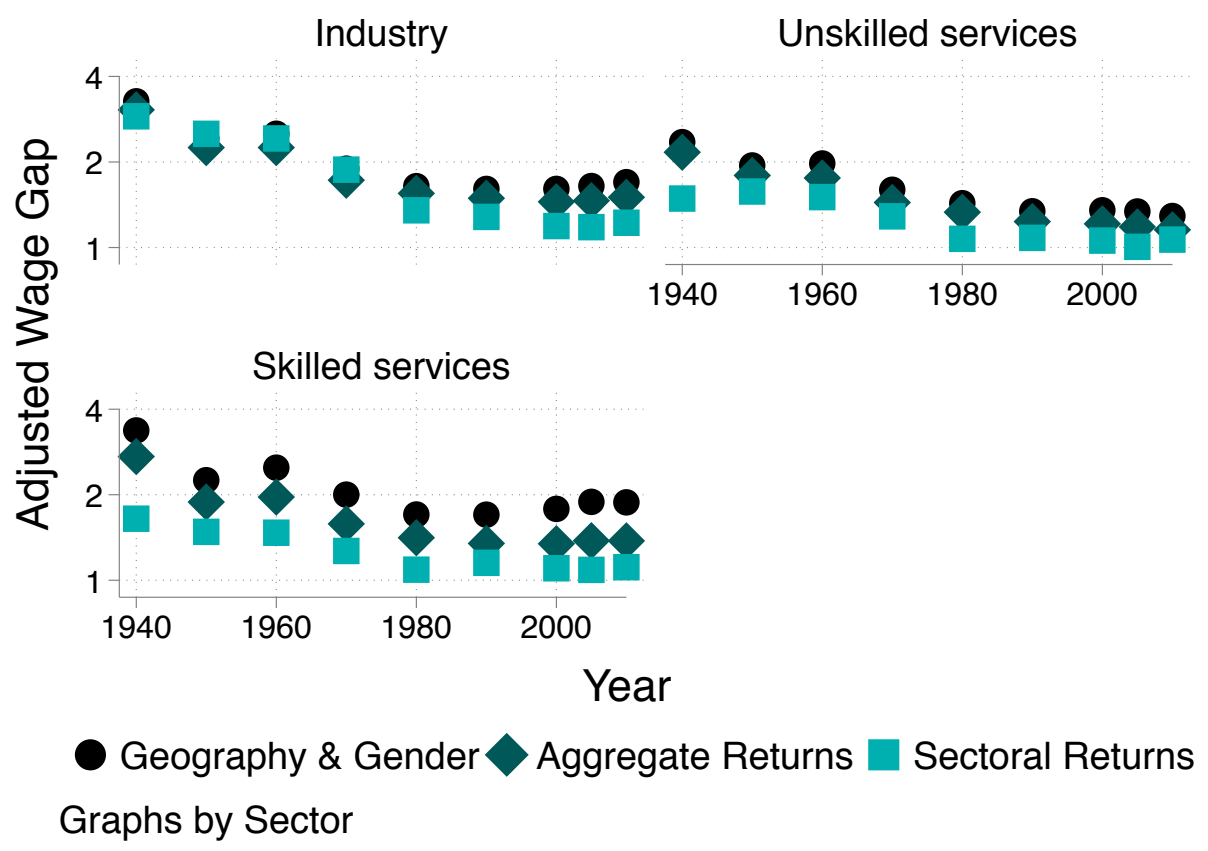


between sector technologies, then the residual wage gaps are entirely due to barriers. Specifically, $\tau_{j}=\left(w_{j}-w_{a}\right) / w_{j}$ where $w_{j}$ and $w_{a}$ are the residual wages in sector $j \in\{i, u, s\}$ and $a$ after controlling for human capital constructed with sector-specific returns. This is what the growth and development literature often assumes.

Table 8: Implied $\tau$

\begin{tabular}{lccc}
\hline & $10^{\text {th }}$ Pctl. & Med. & 90 \\
\hline Non-agriculture & 0.05 & 0.24 & 0.57 \\
1. Industry & 0.19 & 0.42 & 0.88 \\
2. Services & -0.04 & 0.12 & 0.42 \\
2.1 Unskilled services & -0.02 & 0.20 & 0.48 \\
2.2 Skilled services & 0.00 & 0.19 & 0.50 \\
\hline
\end{tabular}

Table 8 reports the implied values of barriers $\tau_{j}$. Interestingly, they are considerably smaller than those calibrated in papers like Restuccia et al. (2008). In fact, the magnitude for the median gaps is perfectly consistent with more benign explanations such as difference in the cost of living between rural and urban areas or differences in the prevalence of the shadow economy in rural and urban areas. Even the maximum gaps do not considerably exceed 100\%, whereas the productivity gaps in our sample of countries are much larger (around a factor of four). These results imply that barriers alone will not at all be able to explain why productivity gaps between non-agriculture and agriculture are so large.

\section{Conclusion}

Our findings suggest that accounting for just one form of selection closes most of the residual wage gap for the U.S. and large parts of the residual wage gaps across countries. We argued above that this implies that barriers play a much smaller quantitative role for the allocation of labor between different sectors than is often argued. This statement implies that the first strand of the structural transformation literature that assumes that structural transformation is the result of efficient reallocation of labor across broad sectors is closer to reality than the second strand that concludes that labor must be allocated inefficiently between sectors.

Our findings also imply that productivity gaps between non-agriculture and agriculture, which are typically much larger than wage gaps, do not manifest themselves in labor markets. This leaves two logical possibilities. First, productivity gaps may result from barriers 
that affect markets other than the labor market. Two obvious examples are subsidies to one sector but not the other and distortion to the land market; see Adamopoulos and Restuccia (2014) on the latter. We think that this is an important topic for further research. Second, measured productivity gaps may be exaggerated because it is notoriously difficult to measure agricultural value added (Herrendorf and Schoellman, 2015). This may imply that actual productivity in agriculture is higher than measured productivity and productivity gaps are more in line with wage gaps.

Our work also has important implications for how to construct human capital at the sectoral level. It shows that one needs to use Mincer returns that are estimated at the sector level, instead of Mincer returns that are estimated at the aggregate level. The reason for this is that Mincer returns that are estimated at the sectoral level capture that unobserved characteristics differ across sectors, which Mincer returns that are estimated at the aggregate level miss by construction.

\section{References}

Adamopoulos, Tasso and Diego Restuccia, "The Size Distribution of Farms and International Productivity Differences," American Economic Review, 2014, 104 (6), 1667-97.

Alvarez, Jorge A., "The Agricultural Wage Gap: Evidence from Brazilian Micro-data," November 2015. mimeo, Princeton University.

Banerjee, Abhijit V. and Esther Duflo, "Growth Theory Through the Lens of Development Economics," in Philippe Aghion and Steven N. Durlauf, eds., Handbook of Economic Growth, Vol. 1A, Elsevier Science, North-Holland Publishers, 2005, chapter 7, pp. $473-554$.

Barro, Robert J. and Jong-Wha Lee, "A New Data Set of Educational Attainment in the World, 1950-2010," Journal of Development Economics, 2010, 104, 184-198.

Beegle, Kathleen, Joachim De Weerdt, and Stefan Dercon, "Migration and economic mobility in Tanzania: Evidence from a tracking survey," Review of Economics and Statistics, 2011, 93 (3), 1010-1033.

Bils, Mark and Peter J. Klenow, "Does Schooling Cause Growth?," American Economic Review, December 2000, 90 (5), 1160-1183. 
Binelli, Chiara, "How the Wage-Education Profile Got More Convex: Evidence from Mexico," The B.E. Journal of Macroeconomics, 2015, 15 (2), 509-560.

Boppart, Timo, "Structural Change and the Kaldor Facts in a Growth Model with Relative Price Effects and Non-Gorman Preferences," Econometrica, 2014, 82, 2167-2196.

Buera, Francisco J. and Joseph P. Kaboski, "The Rise of the Service Economy," American Economic Review, 2012, 102, 2540-2569.

Caselli, Francesco, "Accounting for Cross-Country Income Differences," in Philippe Aghion and Steven N. Durlauf, eds., Handbook of Economic Growth, Vol. 1A, Elsevier, 2005, chapter 9, pp. 679-741.

- and Wilbur John Coleman, "The U.S. Structural Transformation and Regional Convergence: A Reinterpretation," Journal of Political Economy, 2001, 109, 584-616.

Duarte, Margarida and Diego Restuccia, "Relative Prices and Sectoral Productivity," Manuscript, University of Toronto 2014.

Echevarria, Cristina, "Changes in Sectoral Composition Associated with Economic Growth," International Economic Review, 1997, 38, 431-452.

Gollin, Doug, David Lagakos, and Mike Waugh, "The Agricultural Productivity Gap," The Quarterly Journal of Economics, 2014, 129 (2), 939-993.

Herrendorf, Berthold and Todd Schoellman, "Why is Measured Labor Productivity so Low in Agriculture?," Review of Economic Dynamics, 2015, forthcoming.

_, Christopher Herrington, and Ákos Valentinyi, "Sectoral Technology and Structural Transformation," American Economic Journal-Macroeconomics, 2015, 7, 1-31.

_, Richard Rogerson, and Ákos Valentinyi, "Two Perspectives on Preferences and Structural Transformation," American Economic Review, 2013, 103, 2752-2789.

_ , _ , and _ , "Growth and Structural Transformation," in Philippe Aghion and Steven N. Durlauf, eds., Handbook of Economic Growth, Vol. 2, Elsevier, 2014, pp. 855-941.

Hicks, Joan Hamory, Marieke Kleemans, Nicholas Y. Li, and Edward Miguel, "Reevaluating Agricultural Productivity Gaps with Longitudinal Microdata," January 2017. mimeo, UC Berkeley. 
Hnatkovska, Viktoria and Amartya Lahiri, "Structural Transformation and the Rural-Urban Divide," Manuscript, University of British Columbia 2013.

Jorgenson, Dale W. and Marcel P. Timmer, "Structural Change in Advanced Nations: A New Set of Stylised Facts," Scandinavian Journal of Economics, 2011, 113, 1-29.

Kambourov, Gueorgui and Iourii Manovskii, "Rising Occupational and Industry Mobility in the United States: 1968-97," International Economic Review, 2008, 49 (1), $41-79$.

Kongsamut, Piyabha, Sergio Rebelo, and Danyang Xie, "Beyond Balanced Growth," Review of Economic Studies, 2001, 68, 869-882.

Kuznets, Simon, "Modern Economic Growth: Findings and Reflections," Amercian Economic Review, 1973, 63, 247-258.

Lagakos, David and Mike Waugh, "Selection, Agriculture, and Cross-Country Productivity Differences," American Economic Review, 2013, 103, 948-980.

Lemieux, Thomas, "The Mincer Equation Thirty Years After Schooling, Experience, and Earnings," in S. Grossbard, ed., Jacob Mincer, A Pioneer of Modern Labor Economics, Springer Verlag, 2006, pp. 127-145.

Madrian, Brigitte C. and Lars Lefgren, "A Note in Longitudinally Matching Current Population Survey (CPS) Respondents," 1999. NBER Working Paper t0247.

_ and _, "An Approach to Longitudinally Matching Current Population Survey (CPS) Respondents," Journal of Economic and Social Measurement, 2000, 26 (1), 31-62.

McMillan, Margaret and Dani Rodrik, "Globalization, Structural Change, and Economic Growth," in Marc Bachetta and Marion Jansen, eds., Making Globalization Socially Sustainable, Geneva: International Labor Organization and World Trade Organization, 2011, pp. 49-84.

Minnesota Population Center, "Integrated Public Use Microdata Series - International: Version 6.3 [Machine-readable database].," Minneapolis: University of Minnesota. 2014. http://www.ipums.org.

_, "Integrated Public Use Microdata Series, International: Version 6.4," MachineReadable Database, Minneapolis: University of Minnesota 2015. 
Ngai, L. Rachel and Chrisopher A. Pissarides, "Structural Change in a Multisector Model of Growth," American Economic Review, 2007, 9\%, 429-443.

Psacharopoulos, George, "Returns to Investment in Education: A Global Update," World Development, 1994, 22, 1325-1343.

Restuccia, Diego, Dennis T Yang, and Xiaodong Zhu, "Agriculture and Aggregate Productivity: A Quantitative Cross-Country Analysis," Journal of Monetary Economics, March 2008, 55 (2), 234-250.

Rogerson, Richard, "Structural Transformation and the Deterioration of European Labor Market Outcomes," Journal of Political Economy, 2008, 116, 235-259.

Swiecki, Tomasz, "Mobility Costs or Sorting? Sources and Aggregate Implications of Income Gaps across Sectors and Locations in Indonesia," 2014. Manuscript, University of British Columbia.

Vollrath, Dietrich, "How Important are Dual Economy Effects for Aggregate Productivity?," Journal of Development Economics, 2009, 88, 325-334.

Young, Alwyn, "Inequality, the Urban-Rural Gap, and Migration," Quarterly Journal of Economics, 2013, 128, 1727-1785.

_, "Structural Transformation, the Mismeasurement of Productivity Growth, and the Cost Disease of Services," American Economic Review, 2014, 122. 


\section{Appendix: Proofs}

\section{Appendix 1: Proof of Lemma 1}

We start by establishing that $\gamma_{a}=\gamma_{i}$. Suppose to the contrary that $\gamma_{a}<\gamma_{i}$. If $w_{a}<$ $\left(1-\tau_{i}\right) w_{i}$ in addition, then all individuals would choose industry. Hence, it must be that if $w_{a}>\left(1-\tau_{i}\right) w_{i}$. Since there are positive measures of individuals in each sector, there then is a threshold $\chi \in(0, \bar{x} \bar{n})$ such that individuals with $x n=\chi$ are indifferent,

$$
w_{a} \exp \left(\gamma_{a} \chi\right)=\left(1-\tau_{i}\right) w_{i} \exp \left(\gamma_{i} \chi\right)
$$

individuals with $x n<\chi$ prefer agriculture, and individuals with $x n>\chi$ prefer industry. But this implies that conditional on the years of schooling $n \in(0, \bar{n})$, individuals in agriculture are of lower ability than individuals in industry and

$$
\frac{\gamma_{a} \int_{\{x:(x, n) \in \Omega\}} \nu_{a}(x, n) x \mu(d x, n)}{\int_{\{x:(x, n) \in \Omega\}} \nu_{a}(x, n) \mu(d x, n)}<\frac{\gamma_{i} \int_{\{x:(x, n) \in \Omega\}} \nu_{i}(x, n) x \mu(d x, n)}{\int_{\{x:(x, n) \in \Omega\}} \nu_{i}(x, n) \mu(d x, n)}
$$

which is a contradiction to (4). The case $\gamma_{a}>\gamma_{i}$ can be ruled out by a similar argument. Hence, we have established that $\gamma_{a}=\gamma_{i}$.

We now establish that if positive measures of individuals are in each sector and $\gamma_{a}=\gamma_{i}$, then it must be that $\tau_{i}=\left(w_{i}-w_{a}\right) / w_{i}$. For an individual of type $x n$ to choose agriculture it must be that

$$
w_{a} \exp \left(\gamma_{a} x n\right) \geq\left(1-\tau_{i}\right) w_{i} \exp \left(\gamma_{i} x n\right)
$$

For an individual of type $x n$ to choose industry it must be that

$$
w_{a} \exp \left(\gamma_{a} x n\right) \leq\left(1-\tau_{i}\right) w_{i} \exp \left(\gamma_{i} x n\right)
$$

For $\gamma_{a}=\gamma_{i}$, these inequalities simplify to:

$$
\begin{aligned}
& w_{a} \geq\left(1-\tau_{i}\right) w_{i} \\
& w_{a} \leq\left(1-\tau_{i}\right) w_{i}
\end{aligned}
$$

Hence,

$$
w_{a}=\left(1-\tau_{i}\right) w_{i}
$$

QED. 


\section{Appendix 2: Proof of Lemma 2}

Using the same arguments as in the Proof of Lemma 1, we can show that if conditions (5) hold, then it must be that $\gamma_{a}<\gamma_{u}<\gamma_{s}$. Next, we establish that if there are positive masses of individuals in each of the sectors (which is required for positive production), then there are thresholds $0<\chi_{1}<\chi_{2}<\bar{x} \bar{n}$ such that individuals with $x n \in\left[0, \chi_{1}\right)$ choose agriculture or industry, individuals with $x n \in\left(\chi_{1}, \chi_{2}\right)$ choose unskilled services, and individuals with $x n \in\left(\chi_{2}, \bar{x} \bar{n}\right)$ choose skilled services.

$w_{a}>w_{u}>w_{s}$ implies that individuals with $\chi=0$ have a higher income in agriculture than in the two service sectors. Individuals with $\chi=\bar{x} \bar{n}$ have a higher income in unskilled and skilled services than all other individuals. Since some individuals are in each service, it must be that individuals with $\chi=\bar{x} \bar{n}$ prefer both services over agriculture. The monotonicity of the functional form for human capital then implies the following: if an individual prefers agriculture over both services, then all individuals with lower $x n$ do the same; if an individual prefers at least one service over agriculture, then all individuals with higher $x n$ do the same. Hence, there is a threshold $\chi_{1}$ such that to the left individuals prefer agriculture over both services and to the right they prefer at least one service over agriculture. The last step of the proof is to show that there is a $\chi_{2} \in\left(\chi_{1}, \bar{x} \bar{n}\right)$ such to the left individuals prefer unskilled services over skilled services and to the right individuals prefer skilled services over unskilled services. This follows because if an individual prefers unskilled services over skilled services, then all individuals with lower $x n$ do the same and if an individual prefers skilled services over unskilled services, then all individuals with higher $x n$ do the same. QED.

\section{Appendix 3: Proof of Lemma 3}

It suffices to show one inequality, so we focus on $w_{u}<w_{s}$. Individuals with $x n=\chi_{2}$ are indifferent between unskilled and skilled services:

$$
w_{u} \exp \left(\gamma_{u} x n+\beta_{c} c(n)\right)=w_{s}\left(1-\tau_{s}\right) \exp \left(\gamma_{s} x n+\beta_{c} c(n)\right)
$$

Since $\gamma_{u}<\gamma_{s}$, for individuals with $x n \in\left(\chi_{1}, \chi_{2}\right)$ it must be that

$$
w_{u} \exp \left(\gamma_{u} x n+\beta_{c} c(n)\right)>w_{s}\left(1-\tau_{s}\right) \exp \left(\gamma_{s} x n+\beta_{c} c(n)\right)
$$


and for individuals with $x n \in\left(\chi_{2}, \bar{x} \bar{n}\right)$ it must be that

$$
w_{u} \exp \left(\gamma_{u} x n+\beta_{c} c(n)\right)<w_{s}\left(1-\tau_{s}\right) \exp \left(\gamma_{s} x n+\beta_{c} c(n)\right)
$$

Putting (7)-(9) together, we obtain:

$$
\frac{\int_{x n \in\left(\chi_{1}, \chi_{2}\right)} w_{u} \exp \left(\gamma_{u} x n+\beta_{c} c(n)\right) d \mu(x, n)}{\int_{x n \in\left(\chi_{2}, \bar{x} \bar{n}\right)} d \mu(x, n)}<\frac{\int_{x n \in\left(\chi_{2}, \bar{x} \bar{n}\right)} w_{s} \exp \left(\gamma_{s} x n+\beta_{c} c(n)\right) d \mu(x, n)}{\int_{x n \in\left(\chi_{2}, \bar{x} \bar{n}\right)} d \mu(x, n)}
$$

Since production function implies that labor gets paid a share $\theta_{j}$ of value added,, this inequality can be rewritten to:

$$
\frac{\theta_{u} P_{u} Y_{u}}{\int_{x n \in\left(\chi_{1}, \chi_{2}\right)} d \mu(x, n)}<\frac{\theta_{s} P_{s} Y_{s}}{\int_{x n \in\left(\chi_{2}, \bar{x} \bar{n}\right)} d \mu(x, n)}
$$

Defining

$$
\begin{aligned}
L_{u} & \equiv \int_{x n \in\left(\chi_{1}, \chi_{2}\right)} d \mu(x, n) \\
L_{s} & \equiv \int_{x n \in\left(\chi_{2}, \bar{x} \bar{n}\right)} d \mu(x, n)
\end{aligned}
$$

and noting that $W_{j} L_{j}=\theta_{j} p_{j} Y_{j}$, we obtain $W_{u}<W_{s}$. QED

\section{Appendix 4: Proof of Proposition 1}

From the individual problem, we get:

$$
\frac{y_{j}}{y_{j^{\prime}}}=\frac{\alpha_{j}}{\alpha_{j^{\prime}}}\left(\frac{P_{j^{\prime}}}{P_{j}}\right)^{\varepsilon}
$$

Indifference between any two sectors implies that (for the purpose of the proof, we do not restrict taxes):

$$
w_{j}\left(1-\tau_{j}\right)=w_{j^{\prime}}\left(1-\tau_{j^{\prime}}\right)
$$

The firm problem implies:

$$
w_{j}=p_{j} \theta_{j} H_{j}^{\theta_{j}-1}
$$

Putting the last two equations together, we obtain:

$$
\left(1-\tau_{j}\right) P_{j} \theta_{j} H_{j}^{\theta_{j}-1}=\left(1-\tau_{j^{\prime}}\right) P_{j^{\prime}} \theta_{j^{\prime}} H_{j^{\prime}}^{\theta_{j^{\prime}}-1}
$$


Hence:

$$
\frac{P_{j}}{P_{j^{\prime}}}=\frac{\left(1-\tau_{j}\right) \theta_{j}}{\left(1-\tau_{j^{\prime}}\right) \theta_{j^{\prime}}} \frac{H_{j}^{\theta_{j}-1}}{H_{j^{\prime}}^{\theta_{j^{\prime}}-1}}
$$

Substituting that into (12) and rearranging, we get:

$$
\frac{H_{j}^{\theta_{j}(1-\varepsilon)+\varepsilon}}{H_{j^{\prime}}^{\theta_{j^{\prime}}(1-\varepsilon)+\varepsilon}}=\Omega_{j j^{\prime}}
$$

where

$$
\Omega_{j j^{\prime}} \equiv \frac{\alpha_{j}}{\alpha_{j^{\prime}}}\left[\frac{\left(1-\tau_{j}\right) \theta_{j}}{\left(1-\tau_{j^{\prime}}\right) \theta_{j^{\prime}}}\right]^{\varepsilon}
$$

We normalize $w_{a}=1$. To make individuals indifferent between agriculture and industry, we set $w_{i}=1 /\left(1-\tau_{i}\right)$. Given a threshold $\chi_{1}$ such that to the left individuals are either in agriculture or industry, the total human capital in agriculture and manufacturing is given by:

$$
H_{a i}\left(\chi_{1}\right) \equiv \int_{x n \in\left(0, \chi_{1}\right)} \exp \left(\gamma_{a} x n+\beta_{c} c(n)\right) d \mu(x, n)
$$

(13) then implies a unique $\alpha\left(\chi_{1}\right)$ such that

$$
\frac{\left[\alpha\left(\chi_{1}\right)\right]^{\theta_{a}(1-\varepsilon)+\varepsilon}}{\left[1-\alpha\left(\chi_{1}\right)\right]^{\theta_{i}(1-\varepsilon)+\varepsilon}} H_{a i}\left(\chi_{1}\right)^{\left(\theta_{a}-\theta_{i}\right)(1-\varepsilon)}=\Omega_{a i}
$$

Now, define:

$$
\begin{aligned}
H_{a}\left(\chi_{1}\right) & =\alpha\left(\chi_{1}\right) H_{a i}\left(\chi_{1}\right) \\
H_{i}\left(\chi_{1}\right) & =\left[1-\alpha\left(\chi_{1}\right)\right] H_{a i}\left(\chi_{1}\right) \\
H_{u}\left(\chi_{1}, \chi_{2}\right) & =\int_{x n \in\left(\chi_{1}, \chi_{2}\right)} \exp \left(\gamma_{u} x n+\beta_{c} c(n)\right) d \mu(x, n) \\
H_{s}\left(\chi_{2}\right) & =\int_{x n \in\left(\chi_{2}, \bar{x} \bar{n}\right)} \exp \left(\gamma_{s} x n+\beta_{c} c(n)\right) d \mu(x, n)
\end{aligned}
$$

By construction, we satisfy (13) for agriculture and industry. Thus, it remains to be shown that $0<\chi_{1}<\chi_{2}<\bar{x} \bar{n}$ exist that satisfy the last two equations. For any given value of $\chi_{1}$, there is a unique $\chi_{2}\left(\chi_{1}\right)$ such that $(13)$ is satisfied for unskilled and skilled services:

$$
\frac{\left[H_{u}\left(\chi_{1}, \chi_{2}\right)\right]^{\theta_{u}(1-\varepsilon)+\varepsilon}}{\left[H_{s}\left(\chi_{2}\right)\right]^{\theta_{s}(1-\varepsilon)+\varepsilon}}=\Omega_{u s}
$$


To see that note the left-hand side equals zero for $\chi_{2}=\chi_{1}$, equals infinity for $\chi_{2}=\bar{x} \bar{n}$, and is monotonically increasing in $\chi_{2}$.

It remains to show that there is solution $\chi_{1}$ to (13) for agriculture and unskilled services:

$$
\frac{\left[H_{a}\left(\chi_{1}\right)\right]^{\theta_{a}(1-\varepsilon)+\varepsilon}}{\left[H_{u}\left(\chi_{2}\left(\chi_{1}\right)\right)\right]^{\theta_{u}(1-\varepsilon)+\varepsilon}}=\Omega_{a u}
$$

For $\chi_{1}=0$ the left-hand side equals zero and for $\chi_{1}=\bar{x} \bar{n}$ it equals infinity. Continuity and the Intermediate Value Theorem imply there is a solution.

Given the solution $\left(\chi_{1}, \chi_{2}\right)$ just determined, we still have to show that there are service wages per efficiency unit, $\left(w_{u}, w_{s}\right)$, that imply the assumed sorting pattern. Given the assumptions on $\gamma_{j}$, sorting is as assumed if individuals of type $\chi_{1}$ are indifferent between agriculture and unskilled services and individuals of type $\chi_{2}$ are indifferent between unskilled and skilled services:

$$
\begin{aligned}
& \exp \left(\gamma_{a} \chi_{1}+\beta_{c} c\left(\chi_{1}\right)\right)=w_{u} \exp \left(\gamma_{u} \chi_{1}+\beta_{c} c\left(\chi_{1}\right)\right) \\
& w_{u} \exp \left(\gamma_{u} \chi_{2}+\beta_{c} c\left(\chi_{2}\right)\right)=w_{s} \exp \left(\gamma_{s} \chi_{2}+\beta_{c} c\left(\chi_{2}\right)\right)
\end{aligned}
$$

where in a slight abuse of notation, we have denoted the years of college of an individual of type $x n=\chi_{j}$ by $c\left(\chi_{j}\right)$. These two equations have unique solutions for $\left(w_{u}, w_{s}\right)$.

The slope conditions (4) and (5) follow by the assumptions on $\gamma_{j}$ and from the sorting pattern, which implies that for a given $n$, individuals in skilled services have higher average ability than in unskilled services than in agriculture, and for each $n$ individuals in agriculture have the same average ability as in industry.

We have to make sure that for all $n \in(0, \bar{n})$ there are individuals with $n$ years of schooling in each of the sectors. Since the sorting conditions refer to $x n$ only, we have a degree of freedom that allows us to distribute individuals across sectors such that this is the case. Specifically, the individuals in skilled services must satisfy $x n \in\left(\chi_{2}, \bar{x} \bar{n}\right)$. For each $n \in[0, \bar{n}]$, we can allocate some individuals with ability $x>\chi_{2} / n$ to skilled services. The individuals in unskilled services must satisfy $x n \in\left(\chi_{1}, \chi_{2}\right)$. For each $n \in[0, \bar{n}]$, we can allocate some individuals with ability $x \in\left(\chi_{1} / n, \chi_{2} / n\right)$ to unskilled services. The individuals in agriculture or industry must satisfy $x n \in\left(0, \chi_{1}\right)$. For each $n \in[0, \bar{n}]$, we have already allocated some individuals with ability $x \in\left(0, \chi_{1} / n\right)$ to agriculture and industry.

Since we have shown that our equilibrium satisfies all conditions of Lemma 3 , it must be that $W_{a}<W_{u}<W_{s}$. This leaves to show that $W_{i}>W_{a}$. But this is trivially the case here, because the only difference between the two sectors is that $w_{i}>w_{a}$. QED. 


\section{Online Appendix A (Not for Publication): Details about the Data Work}

\section{Online Appendix A.1: Switchers}

In the matched CPS of section 4, we use a rather strict definition of a switcher as someone who switches both sector and narrowly defined occupation. The reason for excluding individuals who switch sector but not occupation is that this "switching" may just reflect noise/measurement error. Luckily, we find that it does not matter much for our results whether or not we use the stricter definition of switchers.

\section{Online Appendix A.2: The Effects of Immigrant Labor}

A common concern with the U.S. data is that the patterns may be explained in large part by the high percentage of immigrants working in the agricultural sector. The fact that the pattern also applies in other countries provides one piece of evidence against this supposition. In this section we re-compute wage and human capital gaps using only natives born in the U.S. We perform this exercise using the monthly CPS files for the years 1994 onward; the variable on citizenship is not available in the monthly CPS before that time.

Table 9: Wage Gaps for all Workers versus Natives (U.S. 1994-2015)

\begin{tabular}{lccc}
\hline & Industry & Unskilled ser. & Skilled ser. \\
\hline All workers & & & \\
Raw & 1.65 & 1.24 & 1.63 \\
Residual aggregate human capital & 1.48 & 1.17 & 1.35 \\
Residual sector-specific human capital & 1.21 & 0.98 & 0.86 \\
\hline Natives & & & \\
Raw & 1.50 & 1.13 & 1.47 \\
Residual aggregate human capital & 1.43 & 1.13 & 1.29 \\
Residual sector-specific human capital & 1.15 & 0.96 & 0.68 \\
\hline
\end{tabular}

${ }^{a} \mathrm{~A}$ gap is the ratio of the value of a variable relative to its value in agriculture.

Our results are given in table 9. As one might expect, the gap in raw and adjusted wages are both smaller if we focus only on natives; part of the low wages in agriculture are explained by the presence of a high proportion of immigrants. Applying a standard human capital correction to the sample of natives would still imply a large residual wage gap of 
43 percent to be explained. Most importantly, however, we find that the sectoral gaps in returns to schooling are actually slightly larger when we focus on natives. For example, the gap in the baseline returns to schooling is 4.1 percent for the native sample as compared to 3.5 percent in the sample including immigrants. Thus, the gap in return to schooling in the U.S. is not explained by immigration. We also find adjusting for these differences more than closes the gap in wages per efficiency unit.

\section{Online Appendix A.3: The Effects of Unions}

In the text we explore the ability of human capital defined in different ways to explain the agricultural wage gap. A concern with this way of proceeding is that our method of constructing human capital with sectoral returns explains the entire gap by definition. Here we perform a simple falsification test to show that this is not the case.

To do so we explore an alternative gap that is widely viewed as arising through market power rather than differences in unobserved human capital and selection, namely the union wage gap. We show results for the monthly CPS files; workers from 1983 onward were asked whether they were union members. We then conduct the same empirical analysis of union wage gaps as we did for sectoral wage gaps. The results are shown in Table 10.

\section{Table 10: Wage Gaps for Union Members Relative to Non-union Mem- bers}

\begin{tabular}{ll}
\hline Raw & 1.28 \\
Adjusted & 1.23 \\
Residual aggregate human capital & 1.22 \\
Residual sector-specific human capital & 1.55 \\
\hline
\end{tabular}

\footnotetext{
${ }^{a}$ A gap is the value of a variable for an average union member relative to it value for an average non-union member.
}

First, the raw union wage gap is sizable; union members earn thirty percent higher hourly wages as compared to non-members. Adjusting for basic demographic information (state and gender) reduces this gap somewhat. Adjusting for schooling using the aggregate returns to school, however, makes almost no difference. Finally, adjusting for differences for the returns to schooling between union and non-union members actually makes the wage gap substantially worse. The reason is simple: the return to schooling for union members is much lower than the return to schooling for non-union members. Given this fact, our 
proposed measure of human capital actually implies that human capital is lower rather than higher for union workers. Figure 7 shows the estimated gap in wages per efficiency unit and returns to schooling for union and non-union workers.

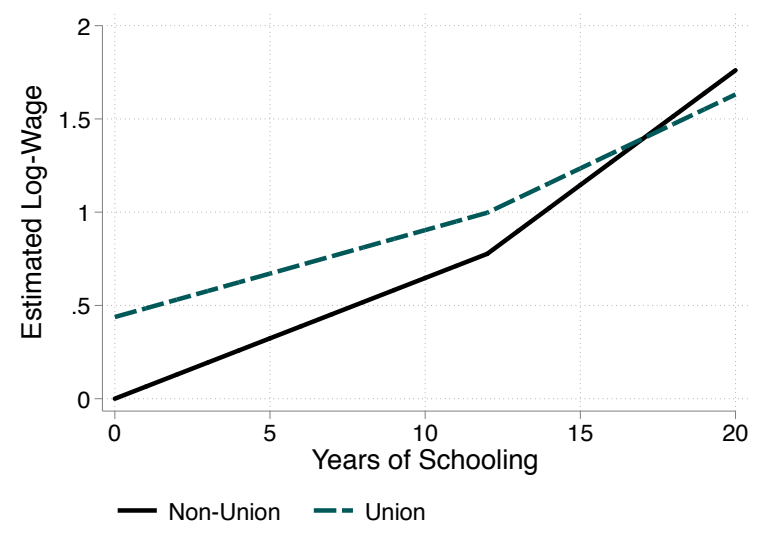

Figure 7: Returns to Schooling Vary with Union Status 


\section{Online Appendix B (Not for Publication): Additional Results}

\section{Online Appendix B.1: U.S. Results for four Sectors - Census}

The 2000 Census was the last to include the "long form" that provides the detailed data on a sample of households. Since 2000 this information has been collected annually from a smaller sample of households through the American Community Survey (ACS). The questions and responses are quite similar, so we combine ACS data for year 2005-2015 with the Censuses of 1980, 1990, and 2000. Tables 11-13 show that the results for Census data are similar to those that we reported in the body of the text for the CPS. This establishes that our results in the text are robust.

Table 11: Gaps in Wages and Schooling (Census U.S.)

\begin{tabular}{lccc}
\hline & Raw wages & Adj. wages & Years of schooling \\
\hline Non-agriculture & 1.56 & 1.63 & 2.72 \\
1. Industry & 1.65 & 1.66 & 1.76 \\
2. Services & 1.53 & 1.62 & 2.99 \\
2.1 Unskilled services & 1.25 & 1.31 & 1.85 \\
2.2 Skilled services & 1.71 & 1.85 & 3.60 \\
\hline
\end{tabular}

${ }^{a}$ A gap is the ratio of the value of a variable relative to its value in agriculture.

Table 12: Gaps in Human Capital and Residual Wages with Aggregate Rates of Return (Census U.S.)

\begin{tabular}{lcccc}
\hline & \multicolumn{2}{c}{ Rate of Return of 0.1 } & \multicolumn{2}{c}{ Estimated rates of return } \\
\cline { 2 - 5 } & Hum. cap. & Res. wages & Hum. cap. & Res. wages \\
\hline Non-agriculture & 1.31 & 1.24 & 1.22 & 1.34 \\
1. Industry & 1.19 & 1.39 & 1.12 & 1.48 \\
2. Services & 1.35 & 1.20 & 1.27 & 1.28 \\
2.1 Unskilled services & 1.20 & 1.09 & 1.11 & 1.18 \\
2.2 Skilled services & 1.43 & 1.29 & 1.35 & 1.38 \\
\hline
\end{tabular}

${ }^{a} \mathrm{~A}$ gap is the ratio of the value relative to its value in agriculture. 
Table 13: Gaps in Human Capital and Residual Wages with Sector-specific Rates of Return (Census U.S.)

\begin{tabular}{lccc}
\hline & Raw wages & Hum. cap. & Res. wages \\
\hline Non-agriculture & 1.56 & 1.42 & 1.15 \\
1. Industry & 1.65 & 1.35 & 1.23 \\
2. Services & 1.53 & 1.52 & 1.07 \\
2.1 Unskilled services & 1.25 & 1.23 & 1.07 \\
2.2 Skilled services & 1.71 & 1.64 & 1.13 \\
\hline
\end{tabular}

${ }^{a} \mathrm{~A}$ gap is the ratio of the value relative to its value in agriculture.

\section{Online Appendix B.2: Results for fifteen Sectors}


Table 14: Raw and Residual Wage Gaps with Sector-specific Returns - CPS

\begin{tabular}{|c|c|c|}
\hline \multicolumn{3}{|l|}{ 1. Industry } \\
\hline \multirow[t]{2}{*}{ Construction } & Raw & 1.60 \\
\hline & Residual & 1.31 \\
\hline \multirow[t]{2}{*}{ Manufacturing } & Raw & 1.65 \\
\hline & Residual & 1.14 \\
\hline \multirow[t]{2}{*}{ Mining } & Raw & 1.99 \\
\hline & Residual & 1.66 \\
\hline \multicolumn{3}{|l|}{ 2.1 Unskilled Services } \\
\hline \multirow[t]{2}{*}{ Hotels \& restaurants } & Raw & 0.93 \\
\hline & Residual & 1.03 \\
\hline \multirow[t]{2}{*}{ Private household services } & Raw & 0.73 \\
\hline & Residual & 1.02 \\
\hline \multirow[t]{2}{*}{ Wholesale \& retail trade } & Raw & 1.26 \\
\hline & Residual & 1.06 \\
\hline \multirow[t]{2}{*}{ Transportation } & Raw & 1.74 \\
\hline & Residual & 1.26 \\
\hline \multicolumn{3}{|l|}{ 2.2 Skilled services } \\
\hline \multirow[t]{2}{*}{ Education } & Raw & 1.60 \\
\hline & Residual & 1.09 \\
\hline \multirow[t]{2}{*}{ Financial services \& insurance } & Raw & 1.82 \\
\hline & Residual & 1.23 \\
\hline \multirow[t]{2}{*}{ Health } & Raw & 1.54 \\
\hline & Residual & 0.67 \\
\hline \multirow[t]{2}{*}{ Utilities } & Raw & 2.04 \\
\hline & Residual & 1.25 \\
\hline \multirow[t]{2}{*}{ Public administration } & Raw & 1.87 \\
\hline & Residual & 1.07 \\
\hline \multirow[t]{2}{*}{ Other services } & Raw & 1.43 \\
\hline & Residual & 0.94 \\
\hline \multirow[t]{2}{*}{ Real estate \& business services } & Raw & 1.65 \\
\hline & Residual & 0.90 \\
\hline
\end{tabular}

${ }^{a}$ A gap is the ratio of the value of a variable relative to its value in agriculture. 
Table 15: Raw and Residual Wage Gaps with Sector-specific Returns - IPUMS International

\begin{tabular}{|c|c|c|c|c|}
\hline & & $10^{\text {th }}$ Pctl. & Med. & $90^{\text {th }}$ Pctl. \\
\hline \multicolumn{5}{|l|}{ 1. Industry } \\
\hline \multirow[t]{2}{*}{ Construction } & Raw & 1.51 & 1.79 & 2.53 \\
\hline & Residual & 1.23 & 1.46 & 2.36 \\
\hline \multirow[t]{2}{*}{ Manufacturing } & Raw & 1.42 & 1.75 & 2.59 \\
\hline & Residual & 1.15 & 1.31 & 1.65 \\
\hline \multirow[t]{2}{*}{ Mining } & Raw & 1.90 & 2.41 & 4.05 \\
\hline & Residual & 1.12 & 1.88 & 2.80 \\
\hline \multicolumn{5}{|l|}{ 2.1 Unskilled Services } \\
\hline \multirow[t]{2}{*}{ Hotels \& restaurants } & Raw & 0.90 & 1.34 & 1.93 \\
\hline & Residual & 1.00 & 1.21 & 1.51 \\
\hline \multirow[t]{2}{*}{ Private household services } & Raw & 0.66 & 0.93 & 1.22 \\
\hline & Residual & 0.83 & 1.10 & 1.29 \\
\hline \multirow[t]{2}{*}{ Wholesale \& retail trade } & Raw & 1.29 & 1.56 & 2.30 \\
\hline & Residual & 1.03 & 1.21 & 1.50 \\
\hline \multirow[t]{2}{*}{ Transportation } & Raw & 1.72 & 2.05 & 3.48 \\
\hline & Residual & 1.16 & 1.49 & 1.91 \\
\hline \multicolumn{5}{|l|}{ 2.2 Skilled services } \\
\hline \multirow[t]{2}{*}{ Education } & Raw & 1.61 & 2.65 & 4.90 \\
\hline & Residual & 0.94 & 1.31 & 1.51 \\
\hline \multirow[t]{2}{*}{ Financial services \& insurance } & Raw & 1.78 & 2.92 & 6.84 \\
\hline & Residual & 0.92 & 1.36 & 2.15 \\
\hline \multirow[t]{2}{*}{ Health } & Raw & 1.27 & 1.99 & 4.04 \\
\hline & Residual & 0.93 & 1.20 & 1.61 \\
\hline \multirow[t]{2}{*}{ Utilities } & Raw & 2.00 & 2.41 & 5.35 \\
\hline & Residual & 1.04 & 1.51 & 2.37 \\
\hline \multirow[t]{2}{*}{ Public administration } & Raw & 1.67 & 2.20 & 4.02 \\
\hline & Residual & 1.06 & 1.49 & 2.02 \\
\hline \multirow[t]{2}{*}{ Other services } & Raw & 1.36 & 1.70 & 2.42 \\
\hline & Residual & 0.99 & 1.19 & 1.42 \\
\hline \multirow[t]{2}{*}{ Real estate \& business services } & Raw & 1.56 & 2.15 & 3.63 \\
\hline & Residual & 0.93 & 1.08 & 1.46 \\
\hline
\end{tabular}

\footnotetext{
${ }^{a}$ A gap is the ratio of the value of a variable relative to its value in agriculture.
} 


\section{Online Appendix B.3: Results from the PSID}

\begin{tabular}{lcccc}
$\begin{array}{l}\text { Table 16: Wage Changes of Switchers from the PSID versus Adjusted Wage } \\
\text { Gaps }\end{array}$ & \multicolumn{4}{c}{} \\
\hline & Observations & Wage Changes & Adjusted \\
& & One Year & Two Years & Wage Gap \\
\hline Agriculture to industry & 153 & 1.01 & 1.21 & 1.83 \\
Agriculture to unskilled services & 72 & 1.11 & 1.34 & 1.67 \\
Agriculture to skilled services & 68 & 1.17 & 1.02 & 1.81 \\
Industry to agriculture & 128 & 0.92 & 0.85 & 0.54 \\
Industry to unskilled services & 1,105 & 0.97 & 0.97 & 0.88 \\
Industry to skilled services & 798 & 0.95 & 0.91 & 0.99 \\
Unskilled services to agriculture & 74 & 0.94 & 0.91 & 0.62 \\
Unskilled services to industry & 1,087 & 1.05 & 0.04 & 0.13 \\
Unskilled to skilled services & 737 & 1.00 & 1.00 & 1.12 \\
Skilled services to agriculture & 47 & 0.96 & 0.96 & 0.55 \\
Skilled services to industry & 721 & 1.01 & 1.20 & 1.01 \\
Skilled to unskilled services & 612 & 0.95 & 0.96 & 0.89
\end{tabular}

Wage Changes refer to the total wage change of switchers relative to workers who remain in the same initial sector the year after the change (one year) or two years after (two years). Observations and adjusted wage gap are measured for the set of workers who can be matched across one year. Roughly half as many workers can be matched across two years, with similar adjusted wage gaps (not shown).

\section{New Material}

We experiment with including the self-employed in our analysis (while maintaining all other sample restrictions). In order to do so, we switch from focusing on wage and salary income to using all earned income. This information is not always available. For example, the monthly CPS files that we used for much of our analysis do not include any information on the income of the self-employed. Also, several of the countries in our database of international censuses do not include any information. However, for the rest of our censuses we have and can use this broader notion of income.

In addition to the fact that it is not available everywhere, the second reason that we exclude the income of the self-employed in our baseline analysis is that it is more difficult to interpret. It is well-known that the self-employed under-report their income. Further, the income that they do report represents not only implicit compensation for their labor 
efforts, but also for any capital or land they bring to their business. Here, we start with the simplest possible approach and simply ignore these issues, taking the reported income at face value. One justification for this is that the bias from underreporting and ignoring non-labor compensation might roughly offset.

\section{Figure 8: Returns to Schooling}
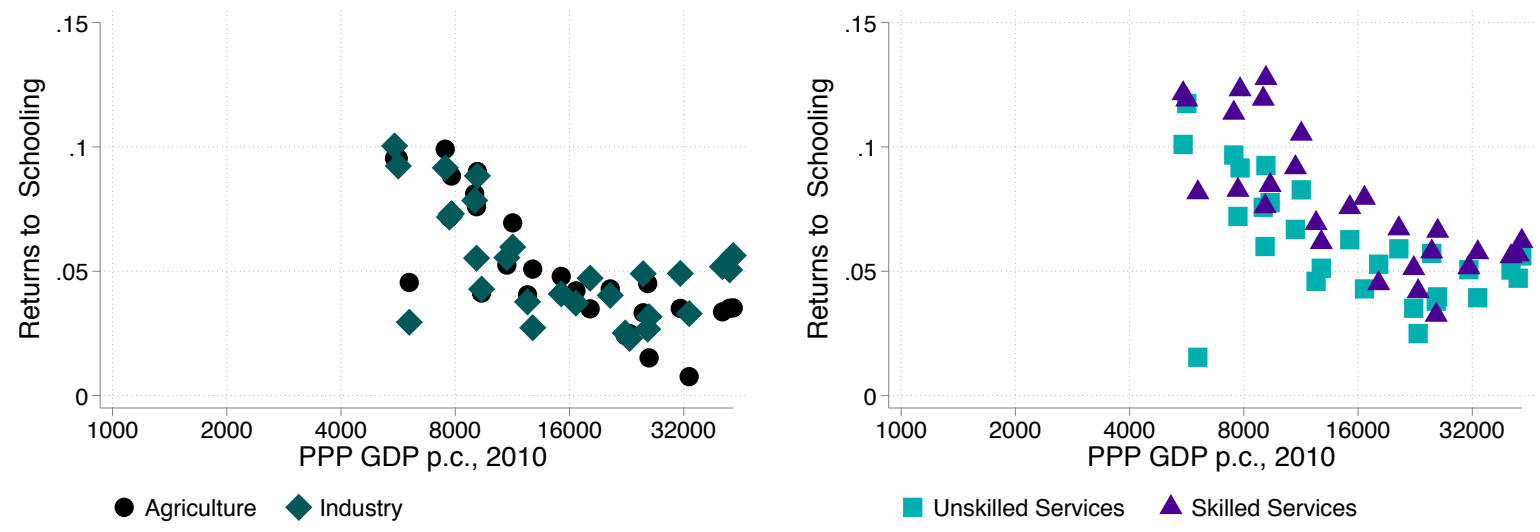

We then re-conduct our analysis for all the countries for which we have this broader measure of income. Our first finding is that estimated sectoral gaps are larger when constructed using all hourly income rather than hourly wages. This can be seen by comparing the first and third columns of Table 17, where we report the median gaps among the subset of countries for which we have both types of information. The income gaps are $0.2-0.3$ larger, which is attributable mostly to the fact that agricultural workers who are self-employed report somewhat lower incomes than those who work for wages and salary. On the other hand, gaps in schooling are relatively similar (not shown), and it is still true that the returns to schooling vary greatly by sector, which skilled services especially showing higher returns, as shown in Figure 8.

Because the large sectoral gaps in returns to schooling remain, we still estimate large sectoral gaps in human capital and hence small adjusted wage or income gaps. In fact, the human capital gaps are somewhat larger when using income than using wages, so that the adjusted income gap is not too much larger than the adjusted wage gap, as can be seen by comparing the second and fourth columns of Table 17. Figure 9 shows the importance of each of the adjustments in turn. 


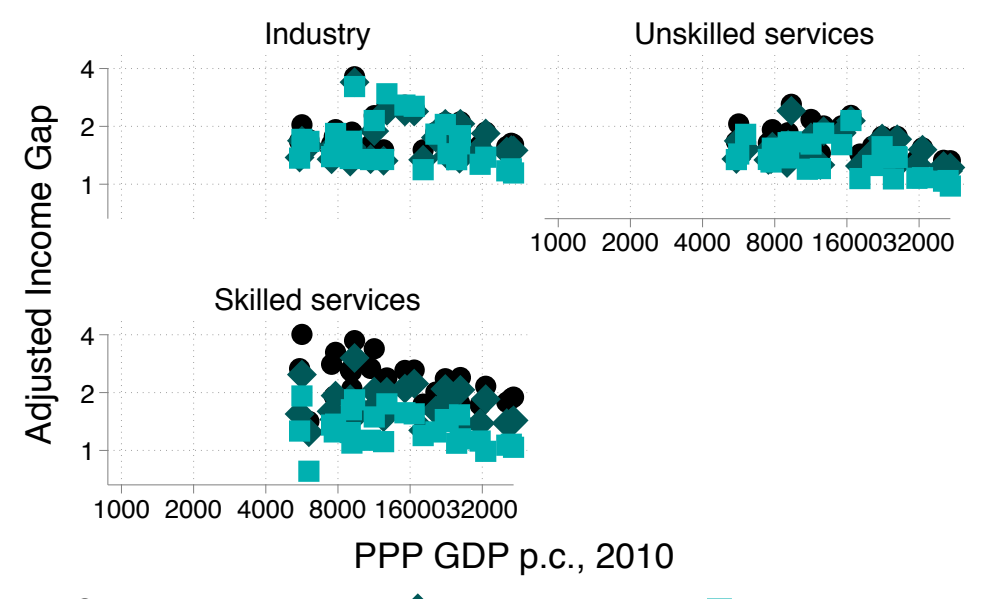

- Geography \& Gender Aggregate Returns Sectoral Returns Graphs by Sector

Figure 9: Income Gaps and Adjusted Income Gaps

Table 17: Median Wage and Income Gaps Across Countries

\begin{tabular}{lcccc}
\hline & Raw Wage Gap & Adj. Wage Gap & Raw Income Gap & Adj. Income Gap \\
\hline Non-Agriculture & 1.78 & 1.23 & 2.05 & 1.37 \\
1. Industry & 1.83 & 1.43 & 2.01 & 1.50 \\
2. Services & 1.87 & 1.12 & 2.03 & 1.28 \\
2.1 Unskilled services & 1.51 & 1.20 & 1.76 & 1.37 \\
2.2 Skilled services & 2.07 & 1.15 & 2.28 & 1.25 \\
\hline
\end{tabular}

